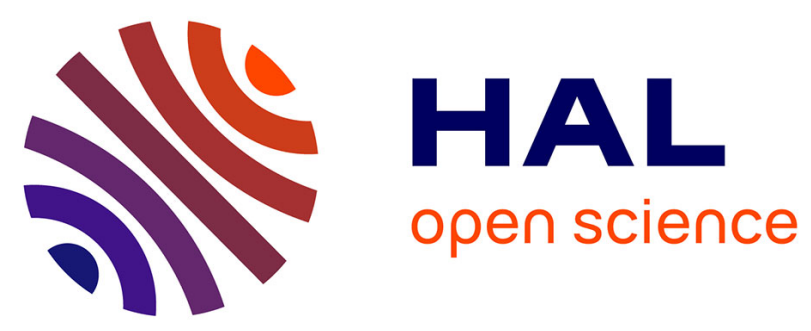

\title{
New Conjugated meso-Tetrafluorenylporphyrin-Cored Derivatives as Fluorescent Two-Photon Photosensitizers for Singlet Oxygen Generation
}

Dandan Yao, Xu Zhang, Amédée Triadon, Nicolas Richy, Olivier Mongin, Mireille Blanchard-Desce, Frédéric Paul, Christine O. Paul-Roth

\section{To cite this version:}

Dandan Yao, Xu Zhang, Amédée Triadon, Nicolas Richy, Olivier Mongin, et al.. New Conjugated meso-Tetrafluorenylporphyrin-Cored Derivatives as Fluorescent Two-Photon Photosensitizers for Singlet Oxygen Generation. Chemistry - A European Journal, 2017, 23 (11), pp.2635-2647. 10.1002/chem.201604654. hal-01475696

HAL Id: hal-01475696

https://hal-univ-rennes1.archives-ouvertes.fr/hal-01475696

Submitted on 20 Mar 2017

HAL is a multi-disciplinary open access archive for the deposit and dissemination of scientific research documents, whether they are published or not. The documents may come from teaching and research institutions in France or abroad, or from public or private research centers.
L'archive ouverte pluridisciplinaire HAL, est destinée au dépôt et à la diffusion de documents scientifiques de niveau recherche, publiés ou non, émanant des établissements d'enseignement et de recherche français ou étrangers, des laboratoires publics ou privés. 


\title{
New Conjugated meso-Tetrafluorenylporphyrin-cored Derivatives as Fluorescent
}

\section{Two-photon Photosensitizers for Singlet Oxygen Generation}

\author{
Dandan Yao, ${ }^{\mathrm{a}, \mathrm{b}} \mathrm{Xu}$ Zhang, ${ }^{\mathrm{a}, \mathrm{b}}$ Amédée Triadon, ${ }^{\mathrm{a}}$ Nicolas Richy, ${ }^{\mathrm{a}}$ \\ Olivier Mongin, ${ }^{a}$ Mireille Blanchard-Desce, ${ }^{\mathrm{c}}$ Frédéric Paul, ${ }^{\mathrm{a}}$ Christine O. Paul-Roth, $*^{\mathrm{a}, \mathrm{b}}$ \\ anstitut des Sciences Chimiques de Rennes (ISCR) - CNRS UMR 6226, Université de Rennes 1, 35042 Rennes Cedex \\ ${ }^{b}$ Institut National des Sciences Appliquées (INSA), 35043 Rennes Cedex, France \\ ${ }^{c}$ Université de Bordeaux, Institut des Sciences Moléculaires (CNRS UMR 5255), 33405 Talence, France. \\ "Dedicated to Professor Jean-Marie Lehn in recognition of his stimulating \\ example in designing molecules for bio-oriented uses"
}

*Corresponding author: christine.paul@univ-rennes1.fr or christine.paul@insa-rennes.fr tel : (+33) (0) 223236372 fax: (+33) (0) 223236372

\begin{abstract}
A series of three conjugated meso-porphyrin dendrimers containing conjugated dendrons featuring 2,7-fluorenyl groups, incorporating overall eight (TFP1), twelve (TFP2) or twenty eight (TFP3) fluorenyl units have been synthesized and characterized. The photophysical properties of these new compounds were studied in the context of photodynamic therapy. The relevant linear and nonlinear optical properties were measured in organic media and useful structure-properties relationships were derived.
\end{abstract}

\section{Keywords}

Porphyrin * Fluorenyl * Fluorescence * Energy Transfer * Dendrimer *

\section{- INTRODUCTION}

Porphyrin, as a macrocycle, is often encountered in nature and constitutes an important functional group. Accordingly, macromolecular assemblies where several porphyrin moieties were linked together by supramolecular interactions ${ }^{[1]}$ or covalent bonds ${ }^{[2]}$ have always attracted much attention for their applications in biochemistry, ${ }^{[3]}$ photophysics, ${ }^{[4]}$ and catalysis. ${ }^{[5]}$ In particular, the optical 
properties of porphyrin derivatives were thoroughly investigated due to the pivotal role of these macrocycles in photosynthesis. For instance, several dendritic porphyrin-based light-harvesting systems presenting impressive efficiencies for light collection and conversion have been reported. ${ }^{[6]}$ Thanks to energy transfer processes, peripheral dendrons play the roles of antenna toward the central porphyrin core in these macromolecules, ${ }^{[7 \mathrm{a}-\mathrm{c}]}$ in which fluorenyl units were often used as efficient active components of the antenna. ${ }^{[7 \mathrm{~d}]}$ Thus, $\mathrm{Bo}^{[8]}$ reported a series of star-shaped porphyrins bearing pendant linear oligofluorene arms and Fréchet ${ }^{[9]}$ reported the synthesis of porphyrin systems with modified fluorenyl units as light-harvesting two-photon absorbers and demonstrated that the antenna effect was facilitated in branched architectures in comparison to linear architectures. ${ }^{[10]}$ Porphyrins possessing fluorenyl arms were also recently used as red fluorophores in hyper branched polymers developed for OLEDs. ${ }^{[11]}$

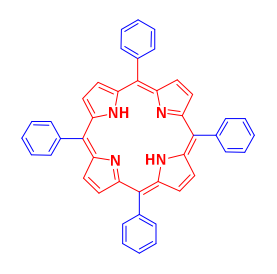

TPP

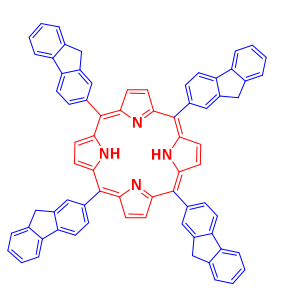

TFP

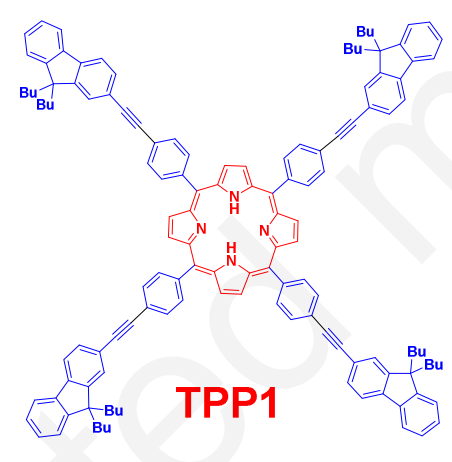

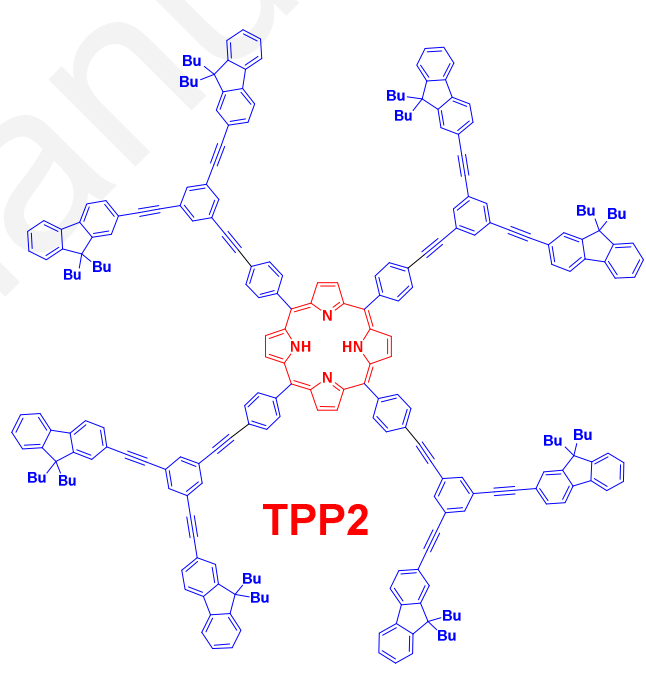

Scheme 1. TPP-cored Porphyrin Dendrimers; TPP1 and TPP2, previously reported and the reference Compounds TPP and TFP.

Motivated by similar goals, we have previously reported the synthesis of meso-tetrafluorenylporphyrin (TFP). ${ }^{[12,13]}$ Remarkably, this simple compound exhibits a high fluorescence quantum yield (23-24\%) compared to the reference tetraphenylporphyrin (TPP, 11-12\%), demonstrating the good capacity of the fluorenyl units to enhance quantum yields by favoring the radiative process over the non-radiative ones. ${ }^{[13 a]}$ In an attempt to further enhance the luminescence quantum yields of the central porphyrin core, we subsequently synthesized two series of substituted meso-substituted TPP-based porphyrin dendrimers incorporating increasing number of fluorenyl units, 
featuring either non-conjugated ether linkers ${ }^{[14]}$ or fully conjugated alkynyl linkers, such as TPP1 and TPP2 (Scheme 1), ${ }^{[15 \mathrm{~d}]}$ and also explored their photophysical properties. ${ }^{[15 \mathrm{e}]}$ We could show that the various fluorene-containing dendrons act as light-harvesting antenna, before transferring their energy to the central porphyrin core which eventually radiatively decays to the ground state by emission of a red fluorescence. Although the emission quantum yields are slightly diminished compared to that for the smaller TFP reference compound, ${ }^{[13 a, 14]}$ we have shown that the brightness of TPP1 and TPP2 (expressed as $\varepsilon . \Phi_{\mathrm{F}}$ ) was much improved over that of TFP, a feature of interest for many applications. More interestingly, we also have evidenced that these dendrimers present remarkable two-photon absorption (TPA) cross-sections, which were significantly larger than those of $\mathbf{T P P},{ }^{[24]}$ especially in the case of compounds with fully conjugated arms, and that TPP1 and TPP2 sensitize oxygen quite efficiently. ${ }^{[15 \mathrm{~d}-\mathrm{e}]}$ When taken together, these various observations strongly suggest that once properly functionalized, ${ }^{[16 a]}$ such (or closely related) molecular architectures might give rise to outstanding photosensitizers for various biomedical applications typical of porphyrin derivatives, such as one- ${ }^{[16 b]}$ or two-photon ${ }^{[16 c-e]}$ photodynamic therapy (PDT). They might even allow more advanced developments, such as two-photon-based theranostic uses. ${ }^{[16-\mathrm{g}]}$

Of particular interest was the fact that, at least for the latter series of dendrimers reported, the synthetic protocol used allowed introducing the fluorenyl units at different positions within the dendrons, either (i) as a terminal chromophore or (ii) as a connecting unit. In this respect, we were now interested in probing the effect of another structural variation on the photophysical properties on such dendrimers, by developing a series of related compounds in which 2,7-fluorenyl groups would be connected directly to the meso positions of the central porphyrin core (i.e. a dendritic architecture analogous to TPP1-2, but featuring TFP instead of TPP as a central core) and still possessing fully conjugated peripheral arms incorporating fluorene units at both terminal and internal positions. We therefore describe hereafter the synthesis of such dendrimers with increasing generations (TFP1, TFP2 and TFP3 in Scheme 2) followed by the study of the photophysical properties of interest. 


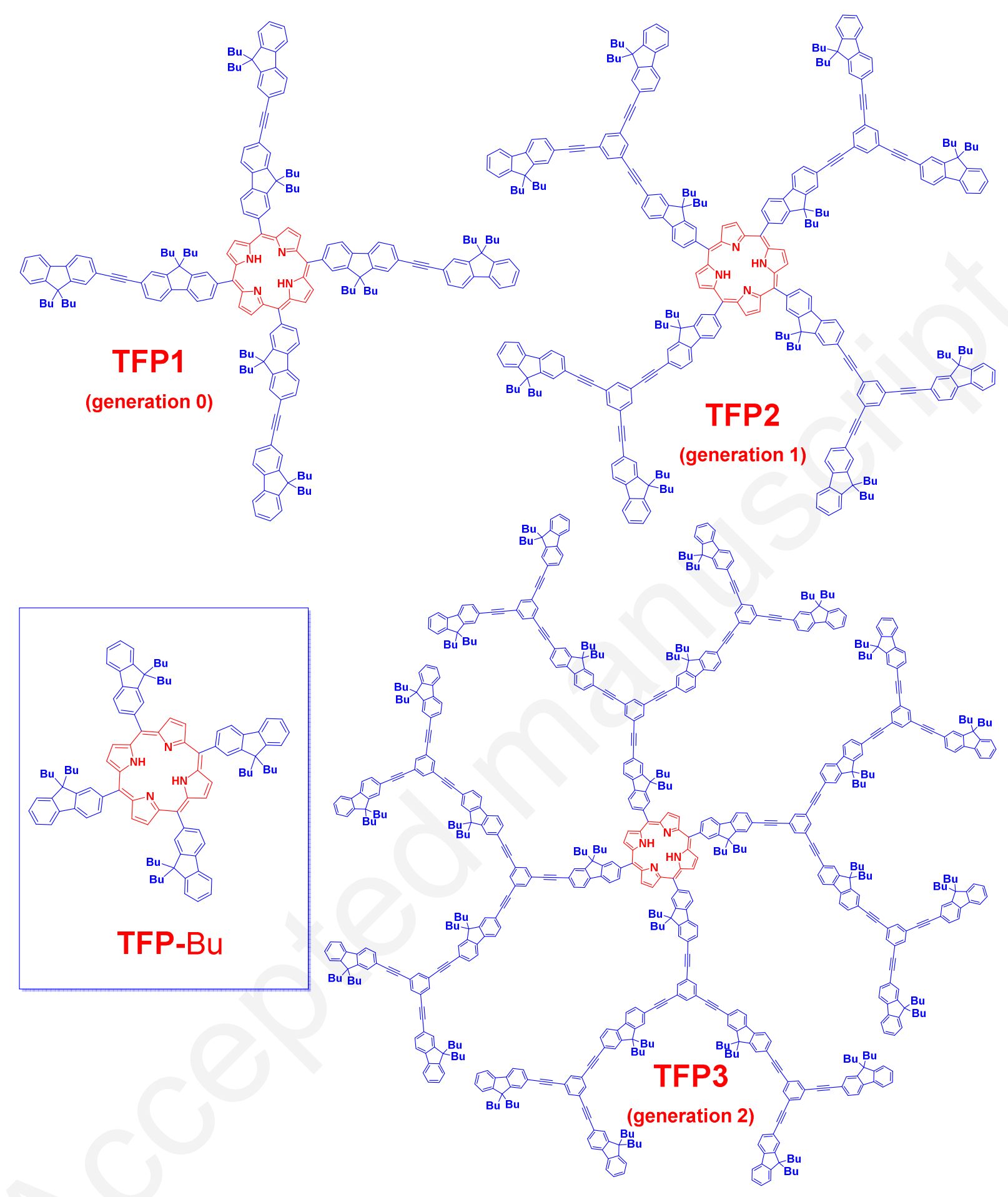

Scheme 2. TFP-cored porphyrin dendrimers TFP1, TFP2 and TFP3 presently targeted and the corresponding reference compounds TFP-Bu.

\section{- RESULTS AND DISCUSSION}

Dendron Synthesis. To synthetically access these new dendrimers, a strategy analogous to that 
previously used for the synthesis of TPP-cored porphyrin dendrimers was adopted which basically involves two steps; (i) the synthesis of dendritic aldehyde precursor and (ii) the formation of the porphyrin core by reaction with pyrrole. ${ }^{[15 d-e]}$

The detailed synthetic methods to obtain the aldehyde with conjugated dendrons are presented in Schemes 3 and 4. As illustrated, the increasing of dendron generation was performed through iterative Sonogashira couplings and Corey-Fuchs reactions, based on related chemistry previously developed in the group. ${ }^{[15]}$ To obtain these new rigid intermediates named D1-3 (as well as the corresponding dendrimers) with suitable solubilities, $n$-butyl groups were appended at the 9 position of the starting 2-bromofluorene. Molecules $\mathbf{1}^{[15 a-b]}$ and $3^{[15 c]}$ have been previously used during the synthesis of TPP-cored porphyrin dendrimers. ${ }^{[15 d-e]}$ The Sonogashira coupling of these alkynes ( $\mathbf{1}$ and $\mathbf{3}$ ) with the bromo-aldehyde $\mathbf{2}^{[17]}$ yielded respectively the new dendrons D1 and D2 in good yields (90\% and 63\% yield, respectively).
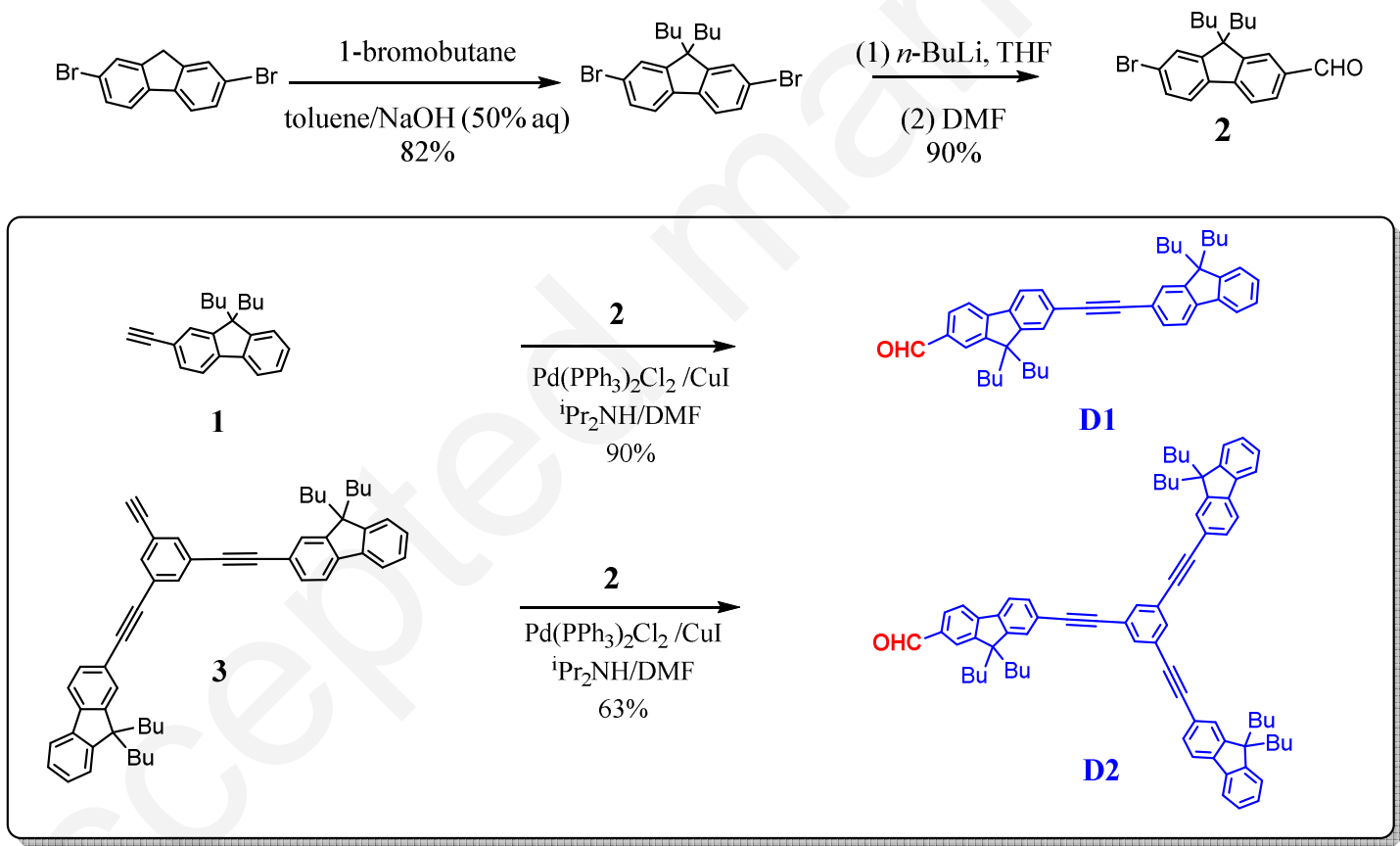

Scheme 3. Synthesis of aldehyde dendrons D1 and D2.

The next generation dendron (D3), with the largest structure, has three layers of fluorenyl units (Scheme 4). By taking D2 as starting material, D3 was obtained by iteration of Sonogashira couplings ${ }^{[18]}$ and Corey-Fuchs reactions. ${ }^{[19]}$ For this sequence of reactions from compound $\mathbf{5}$ to $\mathbf{9}$, the yields of the Corey-Fuchs reactions were typically between $70 \%$ and $90 \%$. Unfortunately the growing intramolecular interactions within the continuously expanding molecular structure increase the difficulty in efficiently 
performing the required Sonogashira couplings between the various alkyne and bromo-aryl intermediates. In the last step, we have therefore decided to use new iodo-aldehyde 4 instead of the classic bromo-aldehyde $\mathbf{2}$ in order to alleviate this cross-coupling reaction by enhancing the reactivity of the halo-aromatic partner. By this mean, the desired dendron D3 was isolated with an acceptable yield (44\%). Notably, access to the starting compound 4 was also optimized; the latter was obtained in a two-step sequence starting by substitution of the two bromine atoms with iodine atoms ( $96 \%$ yield) and by iodine-lithium exchange followed by reaction with DMF (73\% yield). It should be emphasized here that, the reaction time of $n-\mathrm{BuLi}$ with the dibromo derivative ${ }^{[20 \mathrm{a}]}$ should be long enough to form quantitatively the disubstituted product instead of the monosubstituted product in the first step and that the reaction time of $n$-BuLi with the iodo derivative ${ }^{[15 b]}$ should be limited to $20 \mathrm{~min}$ in the second step, as longer reaction times led to decreased yields.

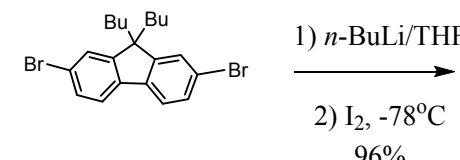

$96 \%$
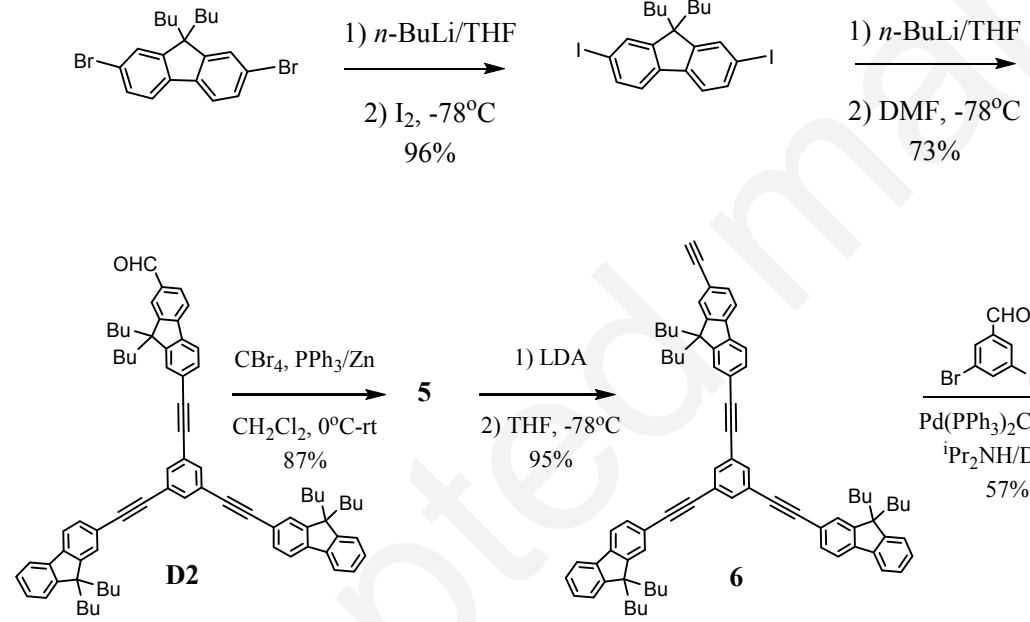

$73 \%$

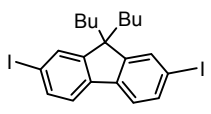

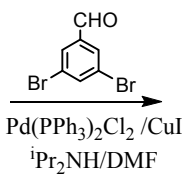

$57 \%$

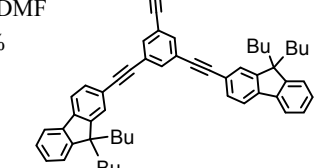

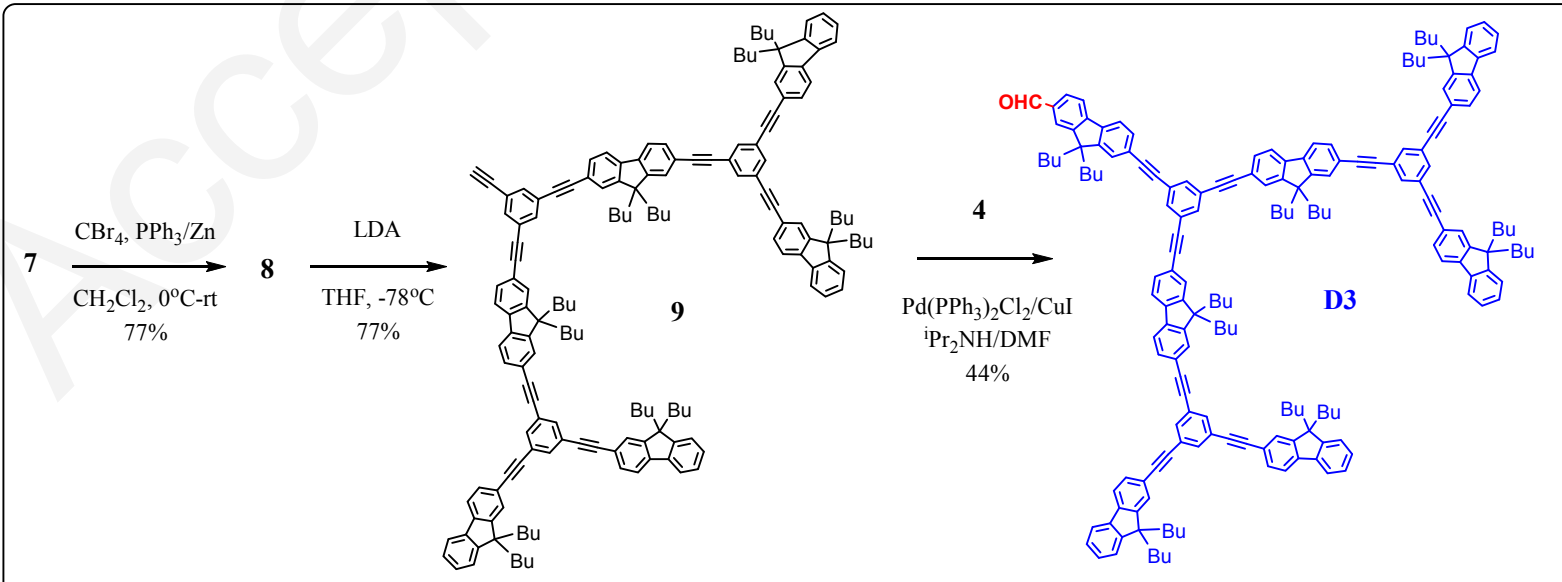

Scheme 4. Synthesis of the aldehyde dendron D3. 
Dendrimer Synthesis. The desired porphyrin-cored dendrimers TFP1, TFP2 and TFP3 were next formed using the Adler-Longo method, ${ }^{[21]}$ by condensation between aldehyde D1-3 and pyrrole in refluxing propionic acid during ca. $5.5 \mathrm{~h}$ (see Scheme 5). After this reaction, TFP1 and TFP2 were isolated by chromatography and obtained as dark purple powders in ca. $19 \%$ yields after further recrystallization from $\mathrm{CHCl}_{3} / \mathrm{MeOH}$ mixtures. Under similar conditions, TFP3 was obtained pure in much lower yields (ca. 1\%) after chromatography. This low yield is probably due to the strong steric hindrance between the large and rigid dendritic parts, which disfavors the successive condensation between aldehyde and pyrrole required during formation of the macrocyclic core of TFP3.

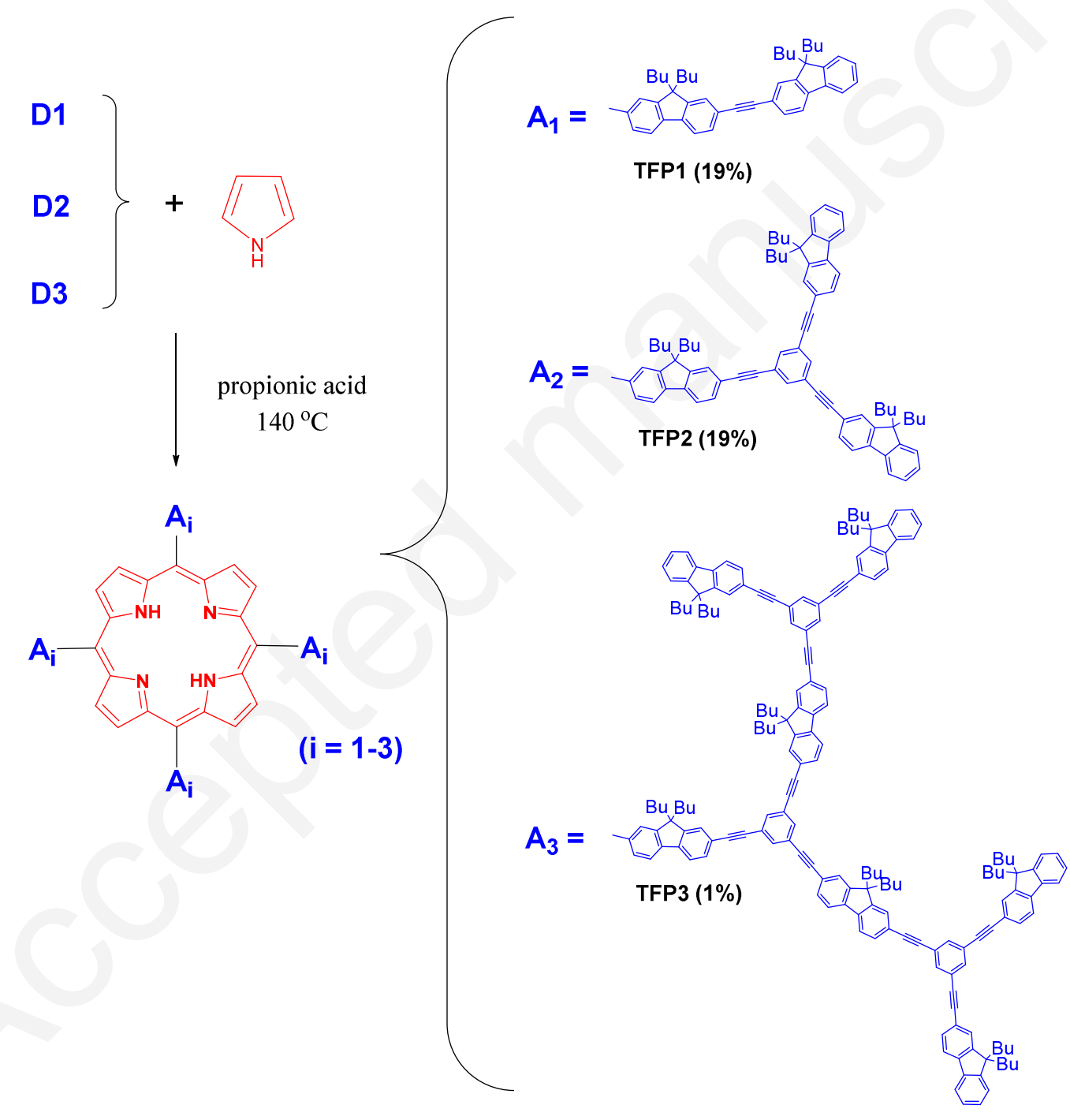

Scheme 5. Synthesis of the TFP-cored Dendrimers TFP1, TFP2 and TFP3.

${ }^{1}$ H NMR Characterization. The aldehyde dendrons D1-3 and dendrimers TFP1-3 were all characterized by ${ }^{1} \mathrm{H} \mathrm{NMR}$ in $\mathrm{CDCl}_{3}(400 \mathrm{MHz})$. 
For these dendrons, we have three diagnostic signatures: (i) the aldehyde proton around $10 \mathrm{ppm}$, (ii) the aromatic protons around 7-8 ppm and (iii) the alkyl protons of the various butyl chains around 0-2 ppm. Taking D2 as example (Figure 1), we detect one proton around $10 \mathrm{ppm}$ which corresponds to the aldehyde function, some signals around 7-8 ppm which integrate for to twenty three protons and belong to protons of the phenyl and the fluorenyl groups, while the four groups of broad multiplets $\mathrm{H}_{\mathrm{a}, \mathrm{b}, \mathrm{c}, \mathrm{d}}$ around 0-2 ppm, which integrate for fifty four protons, are assigned to those of the butyl chains on the various fluorenyl groups. ${ }^{[20 \mathrm{a}]}$

By comparing protons around 7-10 ppm between D1-3, as shown in Figure 2, integration reveals that the signal of the protons belonging to the aldehyde function decreases in the right proportions relative to the others.

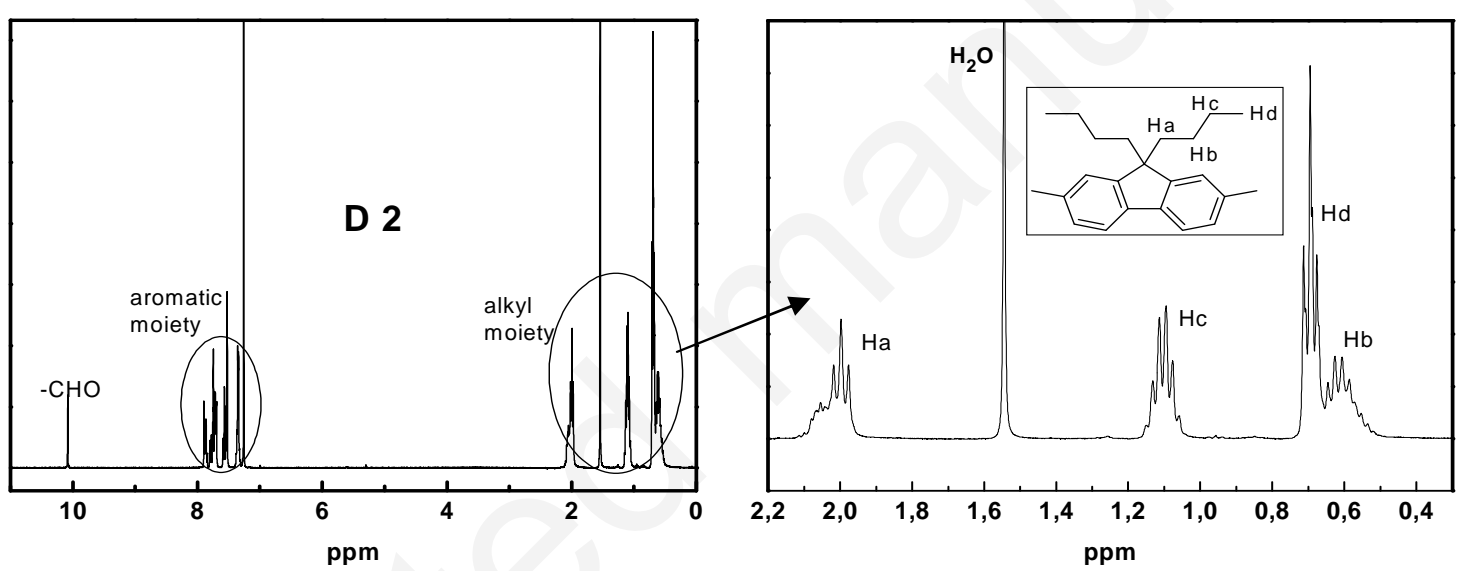

Figure 1. Detailed $400 \mathrm{MHz}{ }^{1} \mathrm{H}$ NMR spectrum of $\mathbf{D} 2$ in $\mathrm{CDCl}_{3}$.

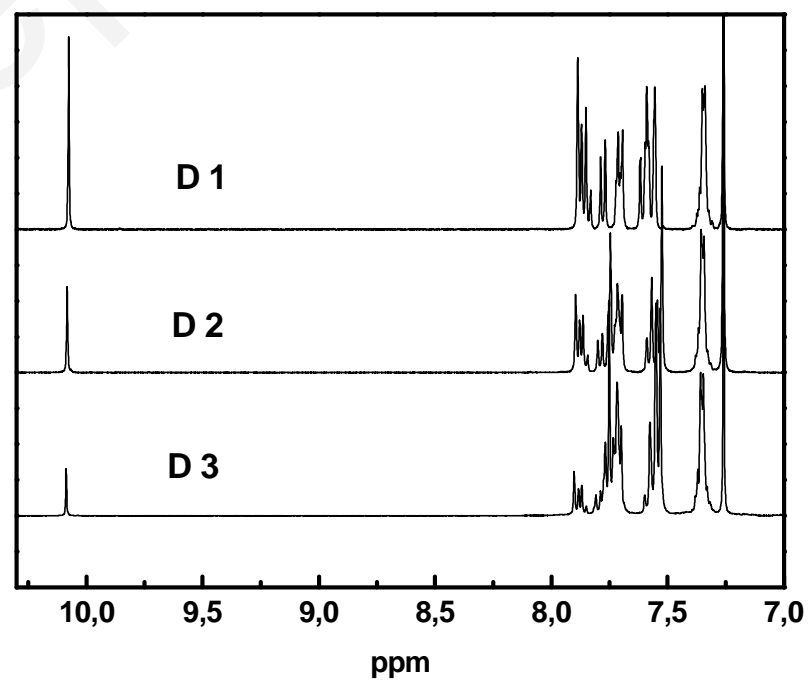

Figure 2. Partial $400 \mathrm{MHz}{ }^{1} \mathrm{H}$ NMR Spectra of aldehyde D1-3 in $\mathrm{CDCl}_{3}$. 
The ${ }^{1} \mathrm{H}$ NMR spectra of dendrimers TFP1-TFP3 also show four diagnostic signatures: (i) the $\beta$-pyrrolic protons of the porphyrin core $\left(\mathrm{H}_{\beta}\right)$ around $9 \mathrm{ppm}$, (ii) the aromatic protons around 7.3-8.3 ppm, (iii) the alkyl protons of the various butyl chains around 0.5-2.2 ppm and (iv) the $-\mathrm{NH}$ protons of porphyrin cavity around $-2.5 \mathrm{ppm}$.

For instance, the full spectrum of TFP2 (Figure 3) features: (i) eight $\mathrm{H}_{\beta}$ protons at $8.94 \mathrm{ppm}$, (ii) three peaks $\left(\mathrm{H}_{\mathrm{A}, \mathrm{B}, \mathrm{C}}\right)$ around $7.9-8.3 \mathrm{ppm}$ belonging to four distinct aromatic protons of the meso-fluorenyl spacers and integrating for sixteen protons (in total), well separated from the remaining 76 aromatic protons of the 1,3,5-phenyl and fluorenyl groups around 7.3-7.8 ppm, (iii) two hundred and sixteen alkyl protons belonging to two distinct butyl chains and (iv) two $-\mathrm{NH}$ protons around -2.5 ppm.

The two distinct sets of four butyl protons integrate for seventy-two protons and hundred and forty-four protons, respectively, and correspond to the protons of the butyl groups located on the terminal 2-fluorenyl groups, at higher field, and to those of the butyl chains on the 2,7-fluorenyl linkers at the lower field.

Notably, for TFP3 which presents three distinct kind of fluorenyl groups in its dendritic arms, the set of four signals belonging to the chemically inequivalent butyl protons of the external 2,7-fluorenyl groups overlaps with that of the butyl protons belonging to the terminal 2-fluorenyl groups (at higher field). As a consequence, only the set of butyl protons belonging to the 2,7-fluorenyl groups directly linked at the meso positions of the central porphyrin ring is distinct at lower field. Their spatial proximity with the central porphyrin core suggests that a ring-current-induced shielding might be at the origin of their spectral differentiation.

In Figure 4, sections of the ${ }^{1} \mathrm{H}$ NMR spectra (7.2-9.0 ppm) of the three dendrimers, are reported. By taking the singlet corresponding to the eight $\mathrm{H}_{\beta}$ as an internal standard for integration, we clearly observe that the signals of the aromatic protons below $7.8 \mathrm{ppm}$ are much more intense for TFP3 than those for TFP2 and TFP1. Accordingly, these aromatic protons must belong to the external part of the dendrons, whereas the aromatic signals above $7.8 \mathrm{ppm}$, of constant integration in the three compounds, must belong to the meso-fluorenyl groups, in line with the assignment previously proposed for TFP2. 


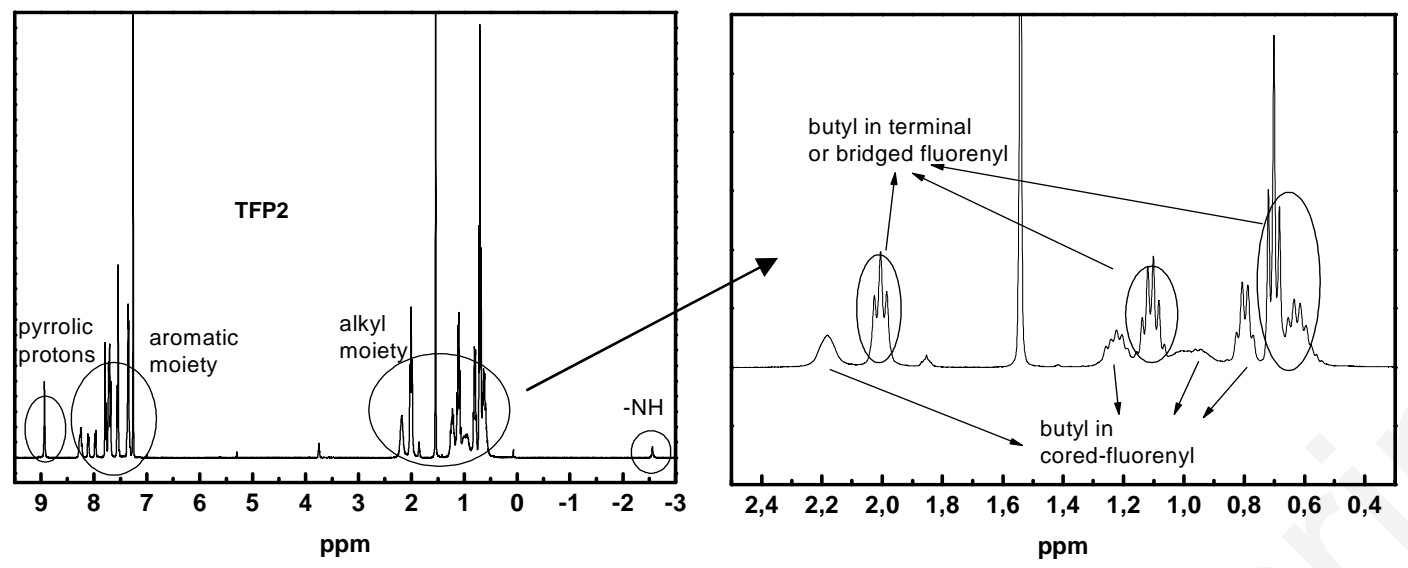

Figure 3. Detailed $400 \mathrm{MHz}{ }^{1} \mathrm{H}$ NMR Spectrum of TFP2 in $\mathrm{CDCl}_{3}$.

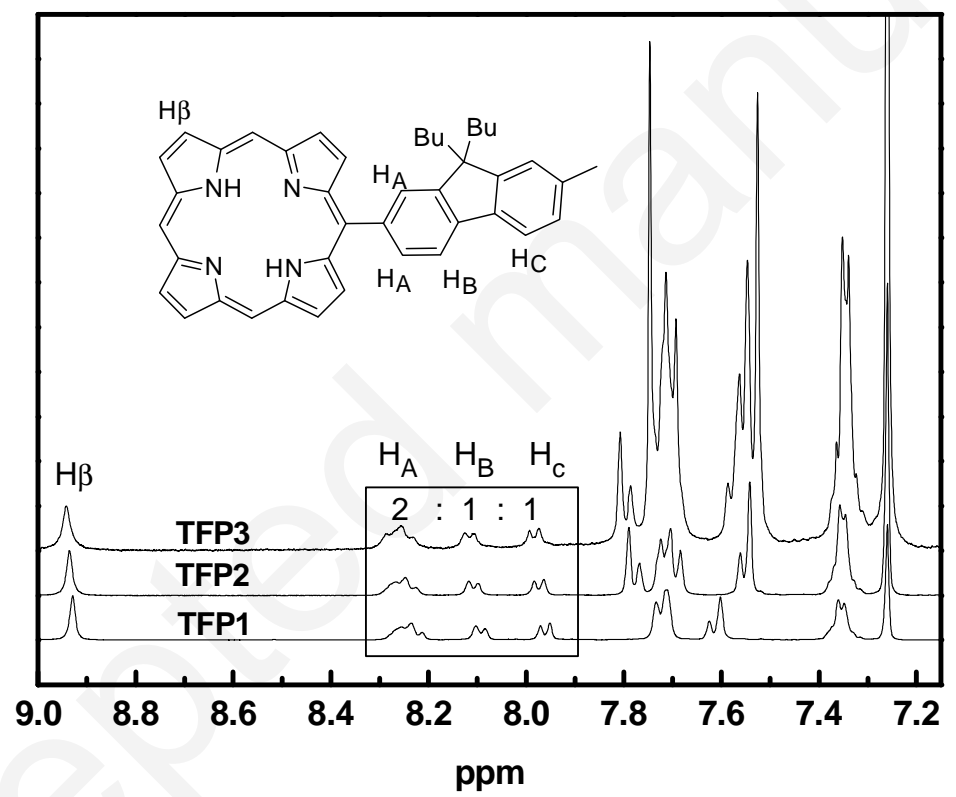

Figure 4. Partial ${ }^{1} \mathrm{H}$ NMR Spectra of TFP1, TFP2 and TFP3 in $\mathrm{CDCl}_{3}$.

Photophysical Properties. UV-visible absorption and emission spectra were next recorded for the new TFP-cored porphyrin dendrimers TFP1-TFP3 in toluene solutions (Table 1). Molecules with similar structures, such as TFP-Bu, TPP, TPP1 and TPP2 ${ }^{[15 \mathrm{~d}-\mathrm{e}]}$ were chosen as references (Scheme 1) to analyze the influence of various aromatic groups at meso-positions on the optical properties of these derivatives.

Absorption Spectra. The new dendrimers TFP1-TFP3 have several characteristic features in their 
UV-visible absorption spectra (Figure 5): (i) an intense Soret-band around $430 \mathrm{~nm}$ and four Q-bands from 520-650 $\mathrm{nm}$ which are typical for free base porphyrin absorptions ${ }^{[12]}$ and (ii) an extra absorption, around 300-400 nm, which corresponds to a $\pi^{*} \leftarrow \pi$ transition of the conjugated dendron. ${ }^{[15 \mathrm{~d}-\mathrm{e}, 22 \mathrm{a}]}$ This absorption, largely fluorenyl-based, is absent for TFP-Bu, suggesting that the unconjugated meso-fluorenyl groups of TFP-Bu absorb below $290 \mathrm{~nm},{ }^{[22 \mathrm{~b}]}$ whereas those of the dendrimers TFP1-TFP3, which conjugate with arylalkynyl segments within the dendrons, are strongly red shifted (330-350 nm) and more intense. ${ }^{[15 d-e]}$ After normalizing the spectra on the intensity of the Soret-band, it is clear that when going from TFP1 to TFP3, this dendron-based absorption increases regularly with increasing generations (Figure 5), while the porphyrin-based transitions (Soret-band and Q-bands) do not show any significant shifts and remain of constant intensity. It should also be noticed that while the intensity of the first dendron-based absorption get stronger with the increasing number of fluorene units, almost no bathochromic shift is observed when progressing from TFP1 to TFP3, suggesting that the conjugation through meta-substitution through the 1,3,5-trisubstituted benzene connectors is not very efficient within each dendron. In spite of that, the intensity of that particular band roughly scales with the number of fluorene groups in the peripheral arms. Taken together, these observations suggest that the phenylethynylfluorene (and also bis(phenylethynyl)fluorene for TFP3) sub-chromophores in the dendrons of TFP2 and TFP3 behave as almost independent units (Scheme 6).

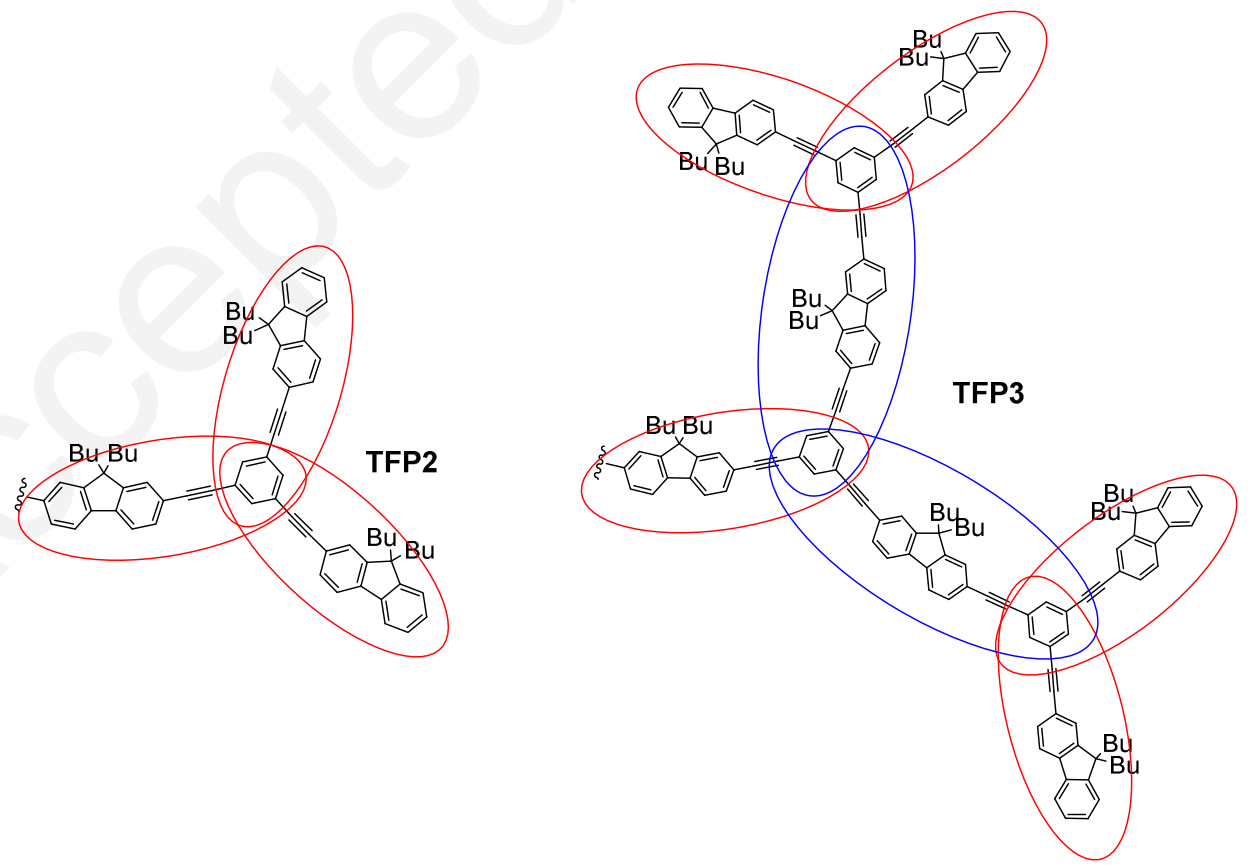

Scheme 6. Phenylethynylfluorene (red) and bis(2,7-phenylethynyl)fluorene (blue) sub-chromophores in the dendrons of TFP2 and TFP3. 
Emission Spectra. Upon excitation in their Soret-band, the dendrimers TFP1-TFP3 and the reference compound TFP-Bu exhibit the characteristic porphyrin emission peaks $\mathrm{Q}(0,0)$ and $\mathrm{Q}(0,1) .{ }^{[22 c]}$ After normalizing the emission intensities of the various compounds on their $\mathrm{Q}(0,0)$ peaks, all four compounds exhibit similar emission spectra (Figure 5). Then, for the dendrimers TFP1-TFP3, the intensity ratios between $\mathrm{Q}(0,0)$ and $\mathrm{Q}(0,1)$ remain constant, as previously observed for the TPP-cored dendrimers. ${ }^{[15 \mathrm{~d}-\mathrm{e}]}$ This strongly suggests that for this new series of porphyrin derivatives, the three different conjugated dendrons, albeit of different size, have certainly a similar influence on the conformation (planarity and shape) of the nearby porphyrin.

Table 1. Photophysical Properties of TFP-Cored Dendrimers and Related Reference Compounds.

\begin{tabular}{|c|c|c|c|c|c|c|}
\hline & \multicolumn{3}{|c|}{ Absorption $^{\mathrm{a}}$} & \multirow{2}{*}{\multicolumn{2}{|c|}{$\begin{array}{c}\text { Emission }^{\mathrm{a}} \\
\lambda_{\mathrm{Ex}}=\text { Soret-band }\end{array}$}} & \multirow{3}{*}{$\begin{array}{c}\text { Quantum } \\
\text { yield }^{\mathrm{b}} \\
(\%)\end{array}$} \\
\hline & \multirow[t]{2}{*}{ Dendron } & Soret & \multirow[t]{2}{*}{ Q-Bands } & & & \\
\hline & & Band & & $\mathrm{Q}(0,0)$ & $\mathrm{Q}(0,1)$ & \\
\hline TFP-Bu & - & 427 & $519,555,596,652$ & 659 & 725 & 20 \\
\hline TFP1 & 339 & 432 & $520,557,598,652$ & 660 & 725 & 24 \\
\hline TFP2 & 333 & 431 & $520,557,597,652$ & 660 & 725 & 24 \\
\hline TFP3 & 350 & 431 & $521,557,598,652$ & 660 & 726 & 23 \\
\hline ТPP & - & 419 & $514,548,590,649$ & 652 & 719 & $11^{\mathrm{c}}$ \\
\hline TPP1 & 324 & 427 & $519,555,597,650$ & 657 & 724 & 20 \\
\hline TPP2 & 328 & 428 & $518,555,594,651$ & 657 & 723 & 19 \\
\hline
\end{tabular}

${ }^{a}$ Experiments were performed in toluene (HPLC grade) with the UV-visible absorption region from 285 to 800 $\mathrm{nm}$ and emission region from 450 to $800 \mathrm{~nm}$.

${ }^{b}$ Fluorescence quantum yields were measured in toluene (HPLC grade) using TPP $(\Phi=11 \%)$ as standard, upon excitation at Soret band (errors are around $\pm 10 \%$ ).

${ }^{c}$ Data from lit. ${ }^{[13 \mathrm{a}]}$

The optical data of TFP-cored dendrimers and their reference compounds are gathered in Table 1. All three new dendrimers TFP1-TFP3 show similar quantum yields $(\sim 24 \%)$ as did TPP-cored porphyrin dendrimers TPP1 and TPP2 $(\sim 20 \%) .{ }^{[15 \mathrm{~d}-\mathrm{e}]}$ When compared to that of TFP-Bu and even more when compared to that of TPP, both devoid of conjugated dendrons, the quantum yields of TFP-cored dendrimers increase significantly. Then, comparison of TFP1-2 with their TPP-cored analogues (TPP1-2), reveals similar trends, although the emission quantum yields of the TFP series are ca. $4 \%$ higher. 


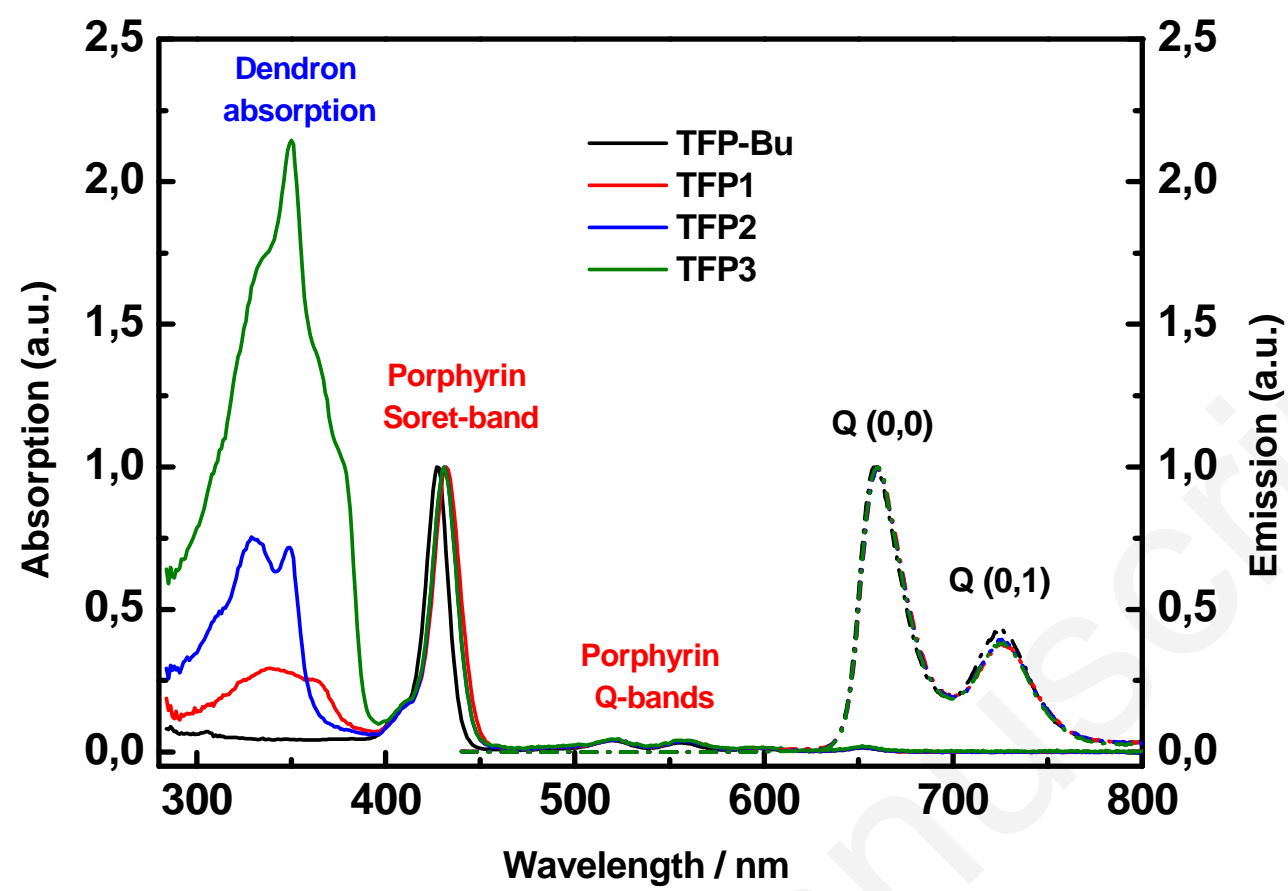

Figure 5. UV-visible Absorption (Solid Line) and Emission Spectra (dash-dotted line) of TFP1-TFP3 and of the reference compound TFP-Bu.

Energy Transfer from the Fluorene Units to the Porphyrin Core. The existence of an energy transfer (ET) between the peripheral dendrons and the central porphyrin core was also probed. Figure 6a presents the emission spectra of TFP1-TFP3 and reference TFP-Bu upon excitation at dendron absorption around 330-350 $\mathrm{nm}$. By excitation in the dendron-based absorption ( 330 $\mathrm{nm})$, the emission spectra of TFP1 and TFP2 show only the red emission (at 660 and $725 \mathrm{~nm}$ ) characteristic of the porphyrin core and no residual blue emission characteristic of the dendron, meaning that the dendron emission is completely quenched through an efficient process most likely corresponding to ET from the dendron to the porphyrin core.

In contrast, the porphyrin TFP3, featuring the largest peripheral dendrons, shows two emissions: (i) a red emission (at 660 and $725 \mathrm{~nm}$ ) similar to that of TFP1 and TFP2, (ii) a residual blue emission appearing around $400 \mathrm{~nm}$, most likely corresponding to a dendron-based emission, suggesting that the corresponding $\pi^{*} \leftarrow \pi$ excited state was not totally quenched by ET. This residual emission might originate from the supplementary layer of peripheral fluorenyl units, which is not present in TFP2, in relation with the less efficient conjugation through meta substitution of the 1,3,5-trisubstituted 
phenylene connectors. These units are also present in TFP2, but the peripheral fluorene layer is closer to the porphyrin acceptor core, allowing therefore for efficient through-space (Förster-type) ET in addition to the (possibly less efficient) through-bond (Dexter-type) ET for this particular compound. In this respect, the good spectral overlap between the Soret absorption band of the porphyrin core and the dendron emission detected in TFP3 indicates that a Förster-type ET can be presently be considered along with a Dexter-type ET process proceeding along the $\pi$-manifold of the dendron.
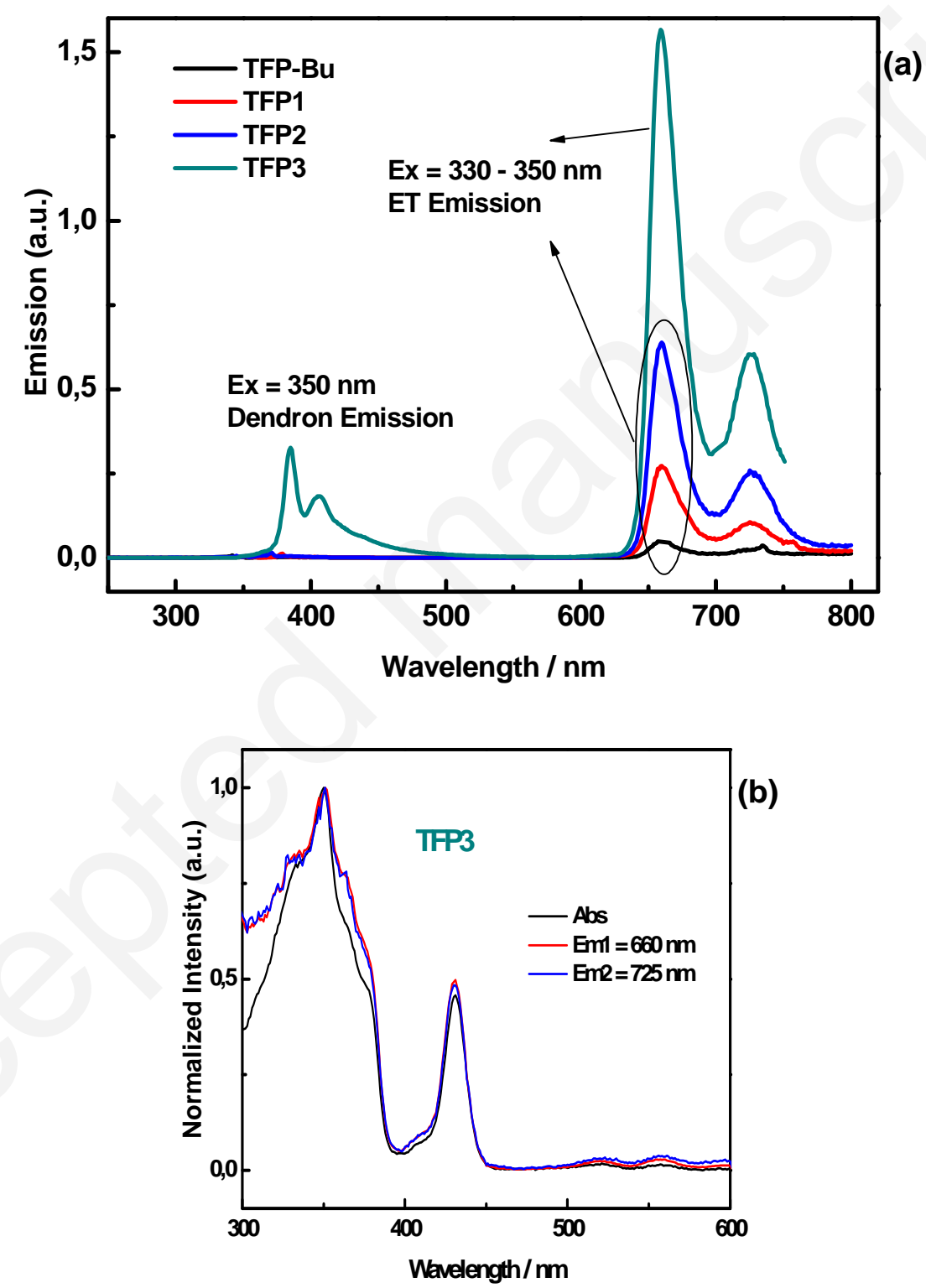

Figure 6. (a) Emission spectra of TFP1-TFP3 upon Excitation at Dendron Absorption $\left(\lambda_{\mathrm{Ex}}=330-350\right.$ nm). (b) Comparison between corrected Excitation Spectra and Absorption Spectrum of TFP3 (by normalizing at the Dendron Peak at $350 \mathrm{~nm}$ ). 
To study in more details the origin of the red emission of TFP3, excitation spectra were measured for the two emission peaks $\left(\lambda_{\mathrm{Em}}=660\right.$ and $725 \mathrm{~nm}$ ) and compared with the absorption spectrum (Figure $6 b)$. These spectra were all normalized at the dendron excitation and absorption intensities $(350 \mathrm{~nm})$. We observe that the excitation spectra of $\mathrm{Q}(0,0)$ at $660 \mathrm{~nm}$ and $\mathrm{Q}(0,1)$ at $725 \mathrm{~nm}$ are both similar to the absorption spectrum, which indicates that TFP3 emissions $\mathrm{Q}(0,0)$ and $\mathrm{Q}(0,1)$ originate from the combined excitation of both the porphyrin core and the dendron meaning that the ET process within TFP3 is very efficient, even if some residual dendron emission can be detected.

Two-Photon Absorption. Based on the fact that important two-photon absorption (TPA) cross-sections had previously been evidenced for TPP1-TPP2 (Scheme 1), we next turned our attention to the two-photon absorption properties of TFP1-TFP3. Taking advantage of the good fluorescence of these TFP-cored dendrimers, their two-photon absorption (TPA) cross-sections were determined by investigating their two-photon excited fluorescence (TPEF) in dichloromethane. Measurements were performed with $10^{-4} \mathrm{M}$ solutions, using a mode-locked Ti:sapphire laser delivering femtosecond pulses, following the experimental protocol described by Xu and Webb. ${ }^{[23]} \mathrm{A}$ fully quadratic dependence of the fluorescence intensity on the excitation power was observed for each sample at all the wavelengths of the spectra shown in Figure 7, indicating that the cross-sections determined are only due to TPA (see ESI, Figure S1).

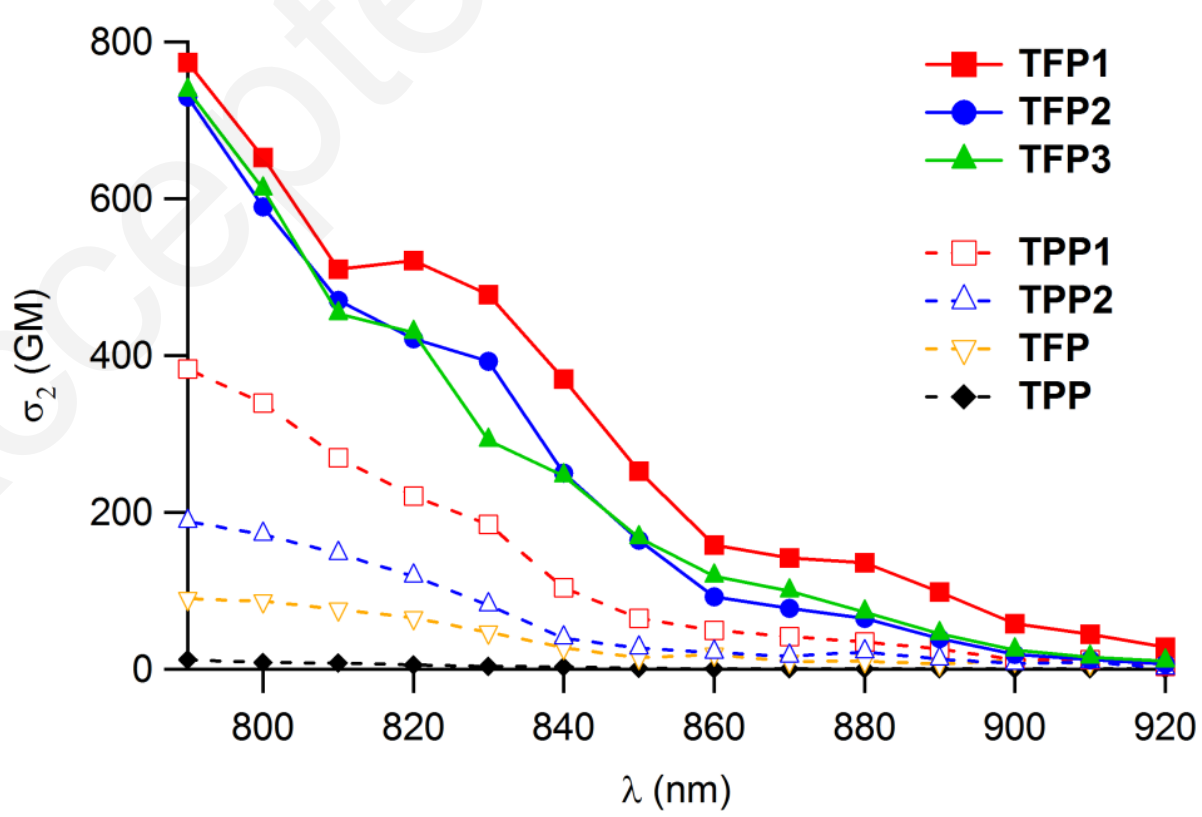

Figure 7. Two-Photon Absorption Spectra for TFP-Cored Dendrimers TFP1-TFP3 (solid lines) and for the Related Compounds (dotted lines) in Dichloromethane. 
A significant increase of the TPA cross-sections compared to that of TPP (12 GM at $790 \mathrm{~nm})$ was observed for all the porphyrins possessing fluorenyl substituents, including the model TFP compound (Table 2). The cross-sections of the dendrimers (both TPP-cored and TFP-cored) were found to be more than one order of magnitude larger than that of TPP. Comparison between TPP-cored and TFP-cored dendrimers reveals that replacing the four phenyl groups at meso-positions by four fluorenyl groups leads to a clear improvement of the TPA properties: as a matter of fact, the cross-sections are doubled when going from TPP1 to TFP1 and quadrupled when going from TPP2 to TFP2. Finally, when comparing TFP-cored dendrimers together, it appears that one alkynyl-fluorenyl group at para-positions to each meso-fluorenyl groups of the porphyrin is much more efficient for TPA than two such groups at meta-positions, confirming that conjugation is rather restricted through the 1,3,5-trisusbtituted benzene connectors. As a result, TFP1, TFP2 and TFP3 exhibit quite similar two-photon absorptivities.

Table 2. Two-Photon Absorption and Brightness Properties of TFP-Cored Dendrimers and Related Reference Compounds.

\begin{tabular}{cccccc}
\hline Compound & $\begin{array}{c}\text { Fluorenes/ } \\
\text { porphyrin }\end{array}$ & $\begin{array}{c}\lambda_{\text {TPA }}{ }^{\max } \\
(\mathrm{nm})\end{array}$ & $\begin{array}{c}\sigma_{2}{ }^{\max } \\
(\mathrm{GM})^{a}\end{array}$ & $\begin{array}{c}\Phi_{F} \cdot \sigma_{2}{ }^{\max } \\
(\mathrm{GM})^{b}\end{array}$ & $\begin{array}{c}\text { Two-photon brightness } \\
\text { enhancement factor }^{c}\end{array}$ \\
\hline TFP & 4 & 790 & 90 & 22 & 17 \\
TFP1 & $\mathbf{8}$ & $\mathbf{7 9 0}$ & $\mathbf{7 7 0}$ & $\mathbf{1 8 5}$ & $\mathbf{1 4 2}$ \\
TFP2 & 12 & 790 & 730 & 175 & $\mathbf{1 3 5}$ \\
TFP3 & 28 & 790 & 740 & 170 & $\mathbf{1 3 1}$ \\
TPP & 0 & 790 & $12^{\mathrm{d}}$ & 1.3 & 1 \\
TPP1 & 4 & 790 & 380 & 76 & 59 \\
TPP2 & 8 & 790 & 190 & 36 & 28 \\
\hline
\end{tabular}

${ }^{a}$ Intrinsic TPA cross-sections measured in $10^{-4} \mathrm{M}$ dichloromethane solutions by TPEF in the femtosecond regime; a fully quadratic dependence of the fluorescence intensity on the excitation power is observed and TPA responses are fully non-resonant.

${ }^{b}$ Maximum two-photon brightness in dichloromethane.

${ }^{c}$ Enhancement factor: $\Phi_{\mathrm{F}} \sigma_{2}^{\max }$ of the compound normalized to that of $\boldsymbol{T P P}$.

${ }^{d}$ Data from lit. ${ }^{[24]}$ 
This increase of the TPA cross-sections combined to the increase of the fluorescence quantum yields leads to very large enhancements of the two-photon brightness $\left(\sigma_{2} . \Phi_{\mathrm{F}}\right)$ for these new dendrimers compared to that of TPP. This particular figure of merit is enhanced by a factor ranging between 17 for model TFP-Bu and 142 for TFP1 (Table 2). Furthermore, it should also be noticed that the enhancements factors of TFP-cored dendrimers (131-142) are 2 to 5 times larger than those of TPP-cored dendrimers (28-59), as TFP-cored dendrimers combine higher TPA cross-sections and higher fluorescence quantum yields. This is quite interesting for imaging purposes.

Oxygen Sensitization. In the continuation of the comparative study between the TPP-based dendrimers and the TFP-based dendrimers, we also wondered about the oxygen-sensitizing capabilities of TFP1-TFP3. The quantum yields of singlet oxygen generation were therefore determined for these dendrimers and compared to those of TPP-cored dendrimers and model TPP and TFP compounds (Table 3). All the new compounds exhibit values higher or comparable to that of TPP, however, the highest quantum yields of singlet oxygen generation remain those previously reported for TPP-cored dendrimers (TPP1). Interestingly, these measurements reveal that the increase of the fluorescence efficiency of the dendrimers (especially in comparison with model TPP) is not obtained at the expense of the singlet oxygen production.

In combination with the notable increase of the TPA cross-sections compared to TPP analogues, such a behavior leads to strong enhancements of the figure of merit of the two-photon excited oxygen sensitization $\left(\Phi_{\Delta} \cdot \sigma_{2}{ }^{\max }\right)$, especially in comparison with that of TPP, ranging between 7 for TFP and 66 for TFP1. TFP-cored dendrimers exhibit clearly higher enhancement factors than TPP-cored dendrimers, in relation with their higher TPA cross-sections and their maintained singlet oxygen quantum yields. These compounds appear therefore well suited for two-photon sensitizing applications, and taking into account their fluorescence properties, for theranostic applications (i.e. combining two-photon fluorescence imaging and photodynamic therapy).

In the perspective of such applications, given their large two-photon brightness, the TFP derivatives constitute therefore quite appealing photosensitizers. In this respect, it should be emphasized that while higher TPA cross-sections have already been reported for other porphyrin-based systems exhibiting more efficient conjugation between the sub-chromophoric units, ${ }^{[25]}$ generally these remarkable performances were accompanied by strong modifications of the other photophysical 
properties of the chromophores, which limited their interest for theranostics. Indeed, most often these two-photon absorbers exhibited a modest to negligible fluorescence, as well as some interfering residual one-photon absorption near $800 \mathrm{~nm}$, which will eventually lead to the loss of the 3D resolution. In contrast, the fluorenyl dendrimers presently reported, with their rather restricted $\pi$-conjugation between the dendrons and the porphyrin core, exhibit an improved trade-off ${ }^{[15 \mathrm{~d}-\mathrm{e} \text { and } 26]}$ between intrinsic TPA cross-sections and fluorescence properties.

Table 3. Oxygen Sensitization Properties of TFP-Cored Dendrimers and Related Reference Compounds.

\begin{tabular}{cccc}
\hline Compound & $\Phi_{\Delta}{ }^{a}$ & $\Phi_{\Delta} \cdot \sigma_{2}{ }^{\max }(\mathrm{GM})^{b}$ & $\begin{array}{c}\text { Two-photon excited oxygen } \\
\text { sensitization enhancement factor }\end{array}$ \\
\hline TFP & 0.60 & 54 & 7 \\
TFP1 & $\mathbf{0 . 6 2}$ & 477 & $\mathbf{6 6}$ \\
TFP2 & 0.61 & 445 & $\mathbf{6 2}$ \\
TFP3 & 0.60 & 444 & $\mathbf{6 2}$ \\
TPP & 0.60 & 7.2 & 1 \\
TPP1 & 0.70 & 266 & 37 \\
TPP2 & 0.65 & 124 & 17 \\
\hline
\end{tabular}

${ }^{a}$ Singlet oxygen production quantum yield determined relative to $\mathbf{T P P}$ in dichloromethane $\left(\Phi_{\Delta}[T P P]=0.60\right)$.

${ }^{b} \Phi_{\Delta} \sigma_{2}^{\max }$ : figure of merit of the two-photon excited singlet oxygen production in dichloromethane.

${ }^{c}$ Enhancement factor: $\Phi_{\Delta} \sigma_{2}^{\max }$ of the compound normalized to that of $\boldsymbol{T P P}$.

\section{- CONCLUSIONS}

The synthesis and characterization of a new family of conjugated meso-tetrafluorenylporphyrin-cored dendrimers, peripherally functionalized with conjugated dendrons containing additional fluorenyl units has been reported here. These new compounds were obtained from the corresponding aldehyde-terminated dendrons and pyrrole under Adler-Longo conditions, while the dendritic precursors were synthesized through iterative Sonogashira couplings ${ }^{[18]}$ and Corey-Fuchs reactions. ${ }^{[19]}$ 
In terms of photophysical properties, these new dendrimers exhibit remarkably high luminescence quantum yields (20-24\%) as free bases, thanks to a very efficient energy transfer from the peripheral fluorenyl units toward the central porphyrin core. This process is plainly apparent for dendrimers TFP1 and TFP2, since the dendron-based emission is totally quenched upon excitation in the intra-ligand absorption characteristic of the dendron and only the red emission characteristic of the porphyrin core is detected. This behavior contrasts with the dual emission observed for the TFP3 compound featuring the largest dendrons at the meso positions. As discussed above, such a behavior was to be expected considering the tilted conformation adopted by the meso-fluorenyl groups bearing the peripheral dendrons. Thus, in spite of that weak conjugation, the one-photon brightness of these compounds upon UV-excitation increases almost linearly with the number of fluorenyl groups in the peripheral arms, in line with the existence of the antenna effect previously mentioned. Furthermore, when compared to the corresponding TPP-cored dendrimers, the TFP-cored dendrimers exhibit much larger intrinsic TPA cross-sections together with increased two-photon brightness upon increasing the size of the $\pi$-manifold, and quite comparable quantum yields for singlet oxygen formation. Furthermore, this structurally-induced semi-disruption of the entire $\pi$-manifold when proceeding from the central core to the dendritic arms, allows preserving an optimal transparency window along the series, especially for the larger generations. As a result, the figures of merit typically used to gauge the efficiency of fluorescent photosensitizers for theranostic uses are now much better than for the TPP-cored dendrimers.

Thus, due their unique structure allowing combining two-photon photodynamic therapy and two-photon fluorescence imaging, TFP-cored dendrimers hold some promise for futures applications in theranostics. In that respect, a closer look at their respective photophysical properties across the TFP series reveals that the para-substituted dendrimer TFP1 is slightly more efficient than TFP2 and TFP3 for such purposes, in spite of its smaller size. Likewise to what had been observed in the TPP series, this indicates that improving further the performances of such kind of architectures does not solely rely on increasing the number of fluorenyl units in the peripheral dendritic antenna, but also in optimizing their internal structure. Work along these lines is now in progress along with the improvement of the hydrophilicity and biocompatibility of these fascinating molecules. 


\section{- EXPERIMENTAL SECTION}

General. Unless otherwise stated, all solvents used in reactions were distilled using common purification protocols, ${ }^{[27]}$ except DMF and ${ }^{\mathrm{i}} \mathrm{Pr}_{2} \mathrm{NH}$ which were dried on molecular sieves $(3 \AA)$. Compounds were purified by chromatography on silica gel using different mixtures of eluents as specified. ${ }^{1} \mathrm{H}$ and ${ }^{13} \mathrm{C}$ NMR spectra were recorded on BRUKER Ascend 400 and 500 at $298 \mathrm{~K}$. The chemical shifts are referenced to internal tetramethylsilane. High-resolution mass spectra were recorded on different spectrometers: a Bruker MicrOTOF-Q II, a Thermo Fisher Scientific Q-Exactive in ESI positive mode and a Bruker Ultraflex III MALDI Spectrometer at CRMPO (centre regional de mesures physiques de l'Ouest) in Rennes. Reagents were purchased from commercial suppliers and used as received. 2-Ethynyl-9,9-dibutyl-fluorene (1), ${ }^{[15]}$ 2,7-dibromo-fluorene, 2,7-dibromo-9,9-dibutyl-

fluorene ${ }^{[20 a]} \quad$ 2,7-diiodo-9,9-dibutyl-fluorene ${ }^{[15 b]}$ and 2,2'-(5-ethynyl-1,3-phenylene) bis(ethyne-2,1-diyl)-bis(9,9-dibutyl- fluoren-2-yl) $(\mathbf{3})^{[15 c]}$ were prepared by adapted procedures following already published preparations. ${ }^{[15]}$ 7-Bromo-9,9-dibutyl-fluorene-2-carbaldehyde (2) was synthesized as described earlier. ${ }^{[18]}$

\section{Synthesis of the Organic Precursors.}

9,9-Dibutyl-7-((9,9-dibutyl-fluoren-2-yl)ethynyl)-fluorene-2-carbaldehyde (D1). In a Schlenk tube, 2 (310 mg, $0.80 \mathrm{mmol}, 1 \mathrm{eq}), 1$ (365 mg, $1.21 \mathrm{mmol}, 1.5 \mathrm{eq}), \mathrm{Pd}\left(\mathrm{PPh}_{3}\right)_{2} \mathrm{Cl}_{2}(17 \mathrm{mg}, 0.02 \mathrm{mmol}, 3 \%$ eq) and $\mathrm{CuI}\left(2.3 \mathrm{mg}, 0.01 \mathrm{mmol}, 1.5 \%\right.$ eq) were dissolved in DMF (5 mL) and ${ }^{\mathrm{i}} \mathrm{Pr}_{2} \mathrm{NH}(5 \mathrm{~mL})$ under argon. The mixture was degassed by freeze-pump-thaw twice and stirred for 2 days at $95{ }^{\circ} \mathrm{C}$. After evaporation of the solvents, the residue was adsorbed on silica and further purified by chromatography using heptane $/ \mathrm{CH}_{2} \mathrm{Cl}_{2}(5: 1)$ mixtures as eluent. The title product was isolated as a white powder (442 $\mathrm{mg}, 90 \%$ yield). ${ }^{1} \mathrm{H} \mathrm{NMR}\left(400 \mathrm{MHz}, \mathrm{CDCl}_{3}, \mathrm{ppm}\right): \delta=10.08$ (s, $\left.1 \mathrm{H}\right), 7.89-7.83(\mathrm{~m}, 3 \mathrm{H}), 7.78(\mathrm{~d}, J=7.6$ $\mathrm{Hz}, 1 \mathrm{H})$, 7.72-7.69 (m, 2H), 7.62-7.56 (m, 4H), 7.37-7.31 (m, 3H), 2.11-1.98 (m, 8H), 1.14-1.05 (m, 8H), $0.68\left(\mathrm{td}, J_{l}=7.4 \mathrm{~Hz}, J_{2}=2.8 \mathrm{~Hz}, 12 \mathrm{H}\right), 0.63-0.48(\mathrm{~m}, 8 \mathrm{H})$. HRMS-ESI: $m / z$ calcd for $\mathrm{C}_{45} \mathrm{H}_{50} \mathrm{ONa}$ : $629.37539[\mathrm{M}+\mathrm{Na}]^{+}$; found 629.3761 .

\section{7-((3,5-Bis((9,9-dibutyl-9H-fluoren-2-yl)ethynyl)phenyl)ethynyl)-9,9-dibutyl-fluorene-2-carb}


aldehyde (D2). In a Schlenk tube, 2 (1.48 g, 3.84 mmol, 1 eq), 3 (2.97 g, 4.22 mmol, 1.1 eq), $\mathrm{Pd}\left(\mathrm{PPh}_{3}\right)_{2} \mathrm{Cl}_{2}(32 \mathrm{mg}, 0.046 \mathrm{mmol}, 1.2 \% \mathrm{eq})$ and $\mathrm{CuI}(4.4 \mathrm{mg}, 0.023 \mathrm{mmol}, 0.6 \%$ eq) were dissolved in DMF $(10 \mathrm{~mL})$ and ${ }^{\mathrm{i}} \mathrm{Pr}_{2} \mathrm{NH}(20 \mathrm{~mL})$ under argon. The mixture was degassed by freeze-pump-thaw twice and stirred for $60 \mathrm{~h}$ at $100{ }^{\circ} \mathrm{C}$. After evaporation of the solvents, the residue was adsorbed on silica and further purified by chromatography using petroleum ether $/ \mathrm{CH}_{2} \mathrm{Cl}_{2}(5: 1)$ mixtures as eluent. The title product was isolated as a white powder $(2.46 \mathrm{~g}, 63 \%$ yield $) .{ }^{1} \mathrm{H} \mathrm{NMR}\left(400 \mathrm{MHz}, \mathrm{CDCl}_{3}, \mathrm{ppm}\right): \delta=$ $10.08(\mathrm{~s}, 1 \mathrm{H}), 7.90-7.84(\mathrm{~m}, 3 \mathrm{H}), 7.79(\mathrm{~d}, J=7.6 \mathrm{~Hz}, 1 \mathrm{H}), 7.75-7.70(\mathrm{~m}, 7 \mathrm{H}), 7.59-7.57(\mathrm{~m}, 2 \mathrm{H})$, 7.54-7.52 (m, 4H), 7.38-7.32 (m, 6H), 2.10-1.98 (m, 12H), 1.15-1.06 (m, 12H), $0.69\left(\mathrm{td}, J_{l}=7.2 \mathrm{~Hz}, J_{2}\right.$ $=2.4 \mathrm{~Hz}, 18 \mathrm{H}), 0.65-0.52(\mathrm{~m}, 30 \mathrm{H})$. HRMS-ESI: $\mathrm{m} / \mathrm{z}$ calcd for $\mathrm{C}_{76} \mathrm{H}_{78} \mathrm{O}: 1006.60472[\mathrm{M}]^{+}$; found 1006.6044 and calcd for $\mathrm{C}_{76} \mathrm{H}_{79} \mathrm{O}: 1007.61254[\mathrm{M}+\mathrm{H}]^{+}$; found 1007.6134.

9,9-dibutyl-7-iodo-fluorene-2-carbaldehyde (4). In a Schlenk tube, a solution of 9,9-dibutyl-2,7-diiodo-9H-fluorene $(523 \mathrm{mg}, 0.99 \mathrm{mmol}, 1 \mathrm{eq})$ in dry THF $(40 \mathrm{~mL})$ was cooled to $-78{ }^{\circ} \mathrm{C}$ using a liquid nitrogen-acetone bath. At low temperature, $n$-BuLi $(0.62 \mathrm{~mL}, 0.99 \mathrm{mmol}, 1 \mathrm{eq})$ was added dropwise to the solution for $10 \mathrm{~min}$. Stirring was kept at $-78^{\circ} \mathrm{C}$ for $20 \mathrm{~min}$, then dry DMF $(1 \mathrm{~mL})$ was injected into the reaction, and the mixture was stirred at $-78{ }^{\circ} \mathrm{C}$ for another $1 \mathrm{~h}$. The cooling bath was removed and the solution was stirred for $2 \mathrm{~h}$ at room temperature. Saturated $\mathrm{NH}_{4} \mathrm{Cl}$ (aq) was added and extraction was performed with ethyl acetate. The solvents were evaporated and the residue was further purified by chromatography using petroleum ether $/ \mathrm{CH}_{2} \mathrm{Cl}_{2}$ mixtures $(5: 1)$ as eluant, affording 4 as a white powder (310 g, 73\% yield). ${ }^{1} \mathrm{H}$ NMR (400 MHz, $\left.\mathrm{CDCl}_{3}, \mathrm{ppm}\right): \delta=10.06$ (s, 1H), 7.87-7.85 (m, 2H), 7.82-7.80 (m, 1H), 7.72-7.71 (m, 2H), $7.52(\mathrm{~d}, J=8.4 \mathrm{~Hz}, 1 \mathrm{H}), 2.06-1.91(\mathrm{~m}, 4 \mathrm{H}), 1.13-1.04(\mathrm{~m}$, $4 \mathrm{H}), 0.67(\mathrm{t}, J=7.2 \mathrm{~Hz}, 6 \mathrm{H}), 0.62-0.46(\mathrm{~m}, 4 \mathrm{H})$.

Intermediate 5. In a Schlenk tube, $\mathrm{PPh}_{3}(1.28 \mathrm{~g}, 4.88 \mathrm{mmol}, 2 \mathrm{eq})$ and $\mathrm{Zn}$ powder (317 mg, 4.88 mmol, 2 eq) was stirred in dry $\mathrm{CH}_{2} \mathrm{Cl}_{2}(15 \mathrm{~mL})$. The mixture was then cooled to $0{ }^{\circ} \mathrm{C}$ using an ice-water bath. $\mathrm{CBr}_{4}(1.62 \mathrm{~g}, 4.88 \mathrm{mmol}, 2 \mathrm{eq})$ was introduced into the Schlenk tube under argon protection and the mixture was kept at low temperature for $2 \mathrm{~min}$. The cooling bath was removed and the mixture was stirred overnight at room temperature. The mixture was cooled again to $0{ }^{\circ} \mathrm{C}$, and a solution of D2 (2.46 $\mathrm{g}, 2.44 \mathrm{mmol}, 1 \mathrm{eq})$ in dry $\mathrm{CH}_{2} \mathrm{Cl}_{2}(15 \mathrm{~mL})$ was then injected under argon protection. The low temperature $\left(0{ }^{\circ} \mathrm{C}\right)$ was kept for $10 \mathrm{~min}$, and then the mixture was stirred overnight in dark at room 
temperature. The reaction mixture was filtered and $\mathrm{CH}_{2} \mathrm{Cl}_{2}$ was evaporated. The resulting residue was adsorbed on silica and further purified by chromatography using heptane / $\mathrm{CH}_{2} \mathrm{Cl}_{2}$ mixtures (100:5), affording 5 as a white powder (2.46 g, 87\% yield). ${ }^{1} \mathrm{H}$ NMR (400 MHz, $\left.\mathrm{CDCl}_{3}, \mathrm{ppm}\right): \delta=7.74-7.69(\mathrm{~m}$, $9 \mathrm{H}), 7.58(\mathrm{~d}, J=6.8 \mathrm{~Hz}, 2 \mathrm{H}), 7.54-7.52(\mathrm{~m}, 7 \mathrm{H}), 7.35-7.31(\mathrm{~m}, 6 \mathrm{H}), 2.00(\mathrm{t}, J=8.0 \mathrm{~Hz}, 12 \mathrm{H}), 1.15-1.06$ (m, 12H), $0.69(\mathrm{t}, J=7.2 \mathrm{~Hz}, 18 \mathrm{H}), 0.60-0.54(\mathrm{~m}, 12 \mathrm{H})$.

Intermediate 6. $n$-BuLi $(1.1 \mathrm{~mL}, 1.75 \mathrm{mmol}, 3 \mathrm{eq})$ was added to a cold $\left(-78^{\circ} \mathrm{C}\right)$ solution of ${ }^{\mathrm{i}} \mathrm{Pr}_{2} \mathrm{NH}(0.25$ $\mathrm{mL}, 1.75 \mathrm{mmol}, 3 \mathrm{eq})$ in dry THF ( $5 \mathrm{~mL})$. After warming up to room temperature carefully, the mixture was injected dropwise into a solution of $5(680 \mathrm{mg}, 0.58 \mathrm{mmol}, 1 \mathrm{eq})$ in dry THF $(10 \mathrm{~mL})$ at $-78{ }^{\circ} \mathrm{C}$, using a liquid nitrogen-acetone bath. The reaction mixture was kept at low temperature for $1 \mathrm{~h}$, then quenched with saturated $\mathrm{NH}_{4} \mathrm{Cl}(5 \mathrm{~mL}$, aq). The cooling bath was removed, and the solution was warmed to room temperature. Extraction was performed with ethyl acetate and the organic layer was dried with $\mathrm{MgSO}_{4}$. Solvents were evaporated, and the residue was adsorbed on silica and further purified by chromatography heptane $/ \mathrm{CH}_{2} \mathrm{Cl}_{2}$ mixtures (100:5) as eluant, affording $\mathbf{6}$ as a white powder (560 mg, 95\% yield). ${ }^{1} \mathrm{H}$ NMR (400 MHz, $\left.\mathrm{CDCl}_{3}, \mathrm{ppm}\right): \delta=7.74-7.65(\mathrm{~m}, 9 \mathrm{H}), 7.54-7.49(\mathrm{~m}, 8 \mathrm{H})$, 7.35-7.34 (m, 6H), $3.17(\mathrm{~s}, 1 \mathrm{H}), 2.00(\mathrm{t}, J=8.0 \mathrm{~Hz}, 12 \mathrm{H}), 1.15-1.06(\mathrm{~m}, 12 \mathrm{H}), 0.70(\mathrm{t}, J=7.4 \mathrm{~Hz}, 18 \mathrm{H})$, 0.65-0.54 (m, 12H). HRMS-ESI: $\mathrm{m} / z$ calcd for $\mathrm{C}_{77} \mathrm{H}_{78}: 1002.6098$ [M] ${ }^{+}$; found 1002.6096 .

Intermediate 7. In a Schlenk tube, a mixture of 3,5-dibromobenzaldehyde (263 mg, $1.00 \mathrm{mmol}, 1$ eq), 6 ( $2 \mathrm{~g}, 2.00 \mathrm{mmol}, 2 \mathrm{eq}), \mathrm{Pd}\left(\mathrm{PPh}_{3}\right)_{2} \mathrm{Cl}_{2}(28 \mathrm{mg}, 0.04 \mathrm{mmol}, 2 \% \mathrm{eq})$ and $\mathrm{CuI}(3.8 \mathrm{mg}, 0.02 \mathrm{mmol}, 1 \%$ eq) were dissolved in DMF (12 mL) and ${ }^{i} \mathrm{Pr}_{2} \mathrm{NH}(12 \mathrm{~mL})$ under argon. The mixture was degassed by freeze-pump-thaw twice and heated for $60 \mathrm{~h}$ at $100{ }^{\circ} \mathrm{C}$. After evaporation of the solvents, the residue was further purified by chromatography using heptane $/ \mathrm{CH}_{2} \mathrm{Cl}_{2}$ mixture $(5: 1)$ as eluant, affording 7 as a light yellow powder (1.2 g, 57\% yield). ${ }^{1} \mathrm{H}$ NMR (400 MHz, $\left.\mathrm{CDCl}_{3}, \mathrm{ppm}\right): \delta=10.05$ (s, $\left.1 \mathrm{H}\right), 8.03$ (s, 3H), 7.75-7.70 (m, 18H), 7.57-7.53 (m, 16H), 7.35-7.31 (m, 12H), 2.05-1.98 (m, 24H), 1.17-1.06 (m, 24H), 0.74-0.55 (m, 60H). HRMS-ESI: $m / z$ calcd for $\mathrm{C}_{161} \mathrm{H}_{158} \mathrm{O}: 2107.23072[\mathrm{M}]^{+}$; found 2107.2243 and calcd for $\mathrm{C}_{161} \mathrm{H}_{158} \mathrm{ONa}$ : $2130.22049[\mathrm{M}+\mathrm{Na}]^{+}$; found 2130.2148 .

Intermediate 8. In a Schlenk tube, $\mathrm{PPh}_{3}(299 \mathrm{mg}, 1.14 \mathrm{mmol}, 2$ eq) and $\mathrm{Zn}$ powder (74 mg, 1.14 mmol, 2 eq) was stirred in dry $\mathrm{CH}_{2} \mathrm{Cl}_{2}(6 \mathrm{~mL})$. The mixture was then cooled to $0{ }^{\circ} \mathrm{C}$, using an ice-water 
bath. $\mathrm{CBr}_{4}(378 \mathrm{mg}, 1.14 \mathrm{mmol}, 2 \mathrm{eq})$ was introduced into the Schlenk tube under argon protection and the mixture was kept at low temperature for $2 \mathrm{~min}$. The cooling bath was removed and the mixture was stirred overnight at room temperature. The mixture was cooled again to $0{ }^{\circ} \mathrm{C}$, and a solution of $7(1.2 \mathrm{~g}$, $0.57 \mathrm{mmol}, 1 \mathrm{eq})$ in dry $\mathrm{CH}_{2} \mathrm{Cl}_{2}(30 \mathrm{~mL})$ was then injected under argon protection. The low temperature $\left(0{ }^{\circ} \mathrm{C}\right)$ was kept for $10 \mathrm{~min}$ and then the mixture was stirred overnight in dark at room temperature. The reaction mixture was filtered and $\mathrm{CH}_{2} \mathrm{Cl}_{2}$ was evaporated. The resulting residue was adsorbed on silica and further purified by chromatography using petroleum ether $/ \mathrm{CH}_{2} \mathrm{Cl}_{2}$ mixtures $(20: 1$ to $10: 1)$ as eluant, affording 8 as a white powder $\left(1.0 \mathrm{~g}, 77 \%\right.$ yield). ${ }^{1} \mathrm{H}$ NMR $\left(400 \mathrm{MHz}, \mathrm{CDCl}_{3}, \mathrm{ppm}\right): \delta=$ 7.81-7.69 (m, 21H), 7.56-7.48 (m, 17H), 7.38-7.32 (m, 12H), 2.05-1.98 (m, 24H), 1.16-1.06 (m, 24H), $0.74-0.54(\mathrm{~m}, 60 \mathrm{H})$.

Intermediate 9. $n$-BuLi $(0.83 \mathrm{~mL}, 1.33 \mathrm{mmol}, 3 \mathrm{eq})$ was added to a cold $\left(-78{ }^{\circ} \mathrm{C}\right)$ solution of ${ }^{\mathrm{i}} \mathrm{Pr}_{2} \mathrm{NH}(0.20 \mathrm{~mL}, 1.33 \mathrm{mmol}, 3 \mathrm{eq})$ in dry THF $(5 \mathrm{~mL})$. After warming up to room temperature carefully, the mixture was injected dropwise into a solution of $\mathbf{8}(1.0 \mathrm{~g}, 0.44 \mathrm{mmol}, 1 \mathrm{eq})$ in dry THF $(10 \mathrm{~mL})$ at -78 ${ }^{\circ} \mathrm{C}$, using a liquid nitrogen-acetone bath. The reaction mixture was kept at low temperature for $1 \mathrm{~h}$, then quenched with saturated aq. $\mathrm{NH}_{4} \mathrm{Cl}(5 \mathrm{~mL})$. The cooling bath was removed, and the solution was warmed to room temperature. Extraction was performed with ethyl acetate and the organic layer was dried with $\mathrm{MgSO}_{4}$. Solvents were evaporated, and the residue was adsorbed on silica and further purified by chromatography using petroleum ether $/ \mathrm{CH}_{2} \mathrm{Cl}_{2}$ mixtures (100:5) as eluant, affording 9 as a pale green powder $\left(720 \mathrm{mg}, 77 \%\right.$ yield). ${ }^{1} \mathrm{H}$ NMR (400 MHz, $\left.\mathrm{CDCl}_{3}, \mathrm{ppm}\right): \delta=7.77-7.67(\mathrm{~m}, 21 \mathrm{H})$, 7.57-7.53 (m, 16H), 7.38-7.32 (m, 12H), $3.14(\mathrm{~s}, 1 \mathrm{H}), 2.05-1.98(\mathrm{~m}, 24 \mathrm{H}), 1.16-1.06(\mathrm{~m}, 24 \mathrm{H})$, 0.74-0.54 (m, 60H). HRMS-ESI: $\mathrm{m} / z$ calcd for $\mathrm{C}_{162} \mathrm{H}_{158}: 2103.23581[\mathrm{M}]^{+}$; found 2103.2308 and calcd for $\mathrm{C}_{162} \mathrm{H}_{158} \mathrm{Na}$ : $2126.22558[\mathrm{M}+\mathrm{Na}]^{+}$; found 2126.2208.

\section{7-((3,5-Bis((7-((3,5-bis((9,9-dibutyl-9H-fluoren-2-yl)ethynyl)phenyl)ethynyl)-9,9-dibutyl-9H-fluo}

ren-2-yl)ethynyl)phenyl)ethynyl)-9,9-dibutyl-9H-fluorene-2-carbaldehyde (D3). In a Schlenk tube, a mixture of 4 (102 mg, $0.24 \mathrm{mmol}, 1 \mathrm{eq}), 9$ (500 mg, $0.24 \mathrm{mmol}, 1 \mathrm{eq}), \mathrm{Pd}\left(\mathrm{PPh}_{3}\right)_{2} \mathrm{Cl}_{2}(10 \mathrm{mg}, 0.14 \mathrm{mmol}$, $6 \%$ eq) and $\mathrm{CuI}\left(1.5 \mathrm{mg}, 0.07 \mathrm{mmol}, 3 \%\right.$ eq) were dissolved in DMF (10 mL) and ${ }^{\mathrm{i}} \operatorname{Pr}_{2} \mathrm{NH}(10 \mathrm{~mL})$ under argon, respectively. The mixture was degassed by freeze-pump-thaw twice and stirred for $90 \mathrm{~h}$ at $95^{\circ} \mathrm{C}$. 
After evaporation of the solvents, the residue was adsorbed on silica and further purified by chromatography using petroleum ether $/ \mathrm{CH}_{2} \mathrm{Cl}_{2}$ mixtures (5:1 to $3: 1$ ) as eluant, affording the title compound as a light yellow powder (250 mg, $66 \%$ yield). ${ }^{1} \mathrm{H} \mathrm{NMR}\left(400 \mathrm{MHz}, \mathrm{CDCl}_{3}, \mathrm{ppm}\right): \delta=10.09$ (s, 1H), 7.90-7.85 (m, 3H), 7.81-7.70 (m, 21H), 7.60-7.53 (m, 19H), 7.38-7.32 (m, 12H), 2.09-1.98 (m, $28 \mathrm{H}), 1.17-1.06(\mathrm{~m}, 28 \mathrm{H}), 0.75-0.54(\mathrm{~m}, 70 \mathrm{H})$. HRMS-ESI: $\mathrm{m} / z$ calcd for $\mathrm{C}_{184} \mathrm{H}_{182} \mathrm{O}: 2407.41852[\mathrm{M}]^{+}$; found 2407.4193 and $\mathrm{C}_{184} \mathrm{H}_{182} \mathrm{O}: 1203.70899[\mathrm{M}]^{++}$; found 1203.7120 .

Porphyrin Dendrimer TFP1. A mixture of dendron D1 (300 mg, $0.49 \mathrm{mmol}, 1 \mathrm{eq}$ ) and propionic acid $(4 \mathrm{~mL})$ was heated to $120{ }^{\circ} \mathrm{C}$ under stirring. A solution of pyrrole $(0.03 \mathrm{~mL}, 0.49 \mathrm{mmol}, 1 \mathrm{eq})$ in propionic acid $(0.6 \mathrm{~mL})$ was then added dropwise. The mixture was refluxed for $5.5 \mathrm{~h}$. After cooling to room temperature, $\mathrm{MeOH}$ was added, leading to a precipitate, which was filtered. Purification by chromatography eluting with petroleum ether $/ \mathrm{CH}_{2} \mathrm{Cl}_{2}$ mixtures $(5: 1)$, afforded a red powder, which was recrystallized from $\mathrm{CHCl}_{3}$ and $\mathrm{MeOH}$, leading to TFP1 as a purple powder (60 mg, $19 \%$ yield). ${ }^{1} \mathrm{H}$ NMR (400 MHz, $\left.\mathrm{CDCl}_{3}, \mathrm{ppm}\right): \delta=8.93$ (s, 8H), 8.26-8.21 (m, 8H), 8.09 (d, $\left.J=7.6 \mathrm{~Hz}, 4 \mathrm{H}\right), 7.96$ (d, $J$ $=8.0 \mathrm{~Hz}, 4 \mathrm{H}), 7.73-7.71(\mathrm{~m}, 16 \mathrm{H}), 7.62-7.60(\mathrm{~m}, 8 \mathrm{H}), 7.36-7.32(\mathrm{~m}, 12 \mathrm{H}), 2.17(\mathrm{broad}, 16 \mathrm{H}), 2.02(\mathrm{t}, J$ $=8.0 \mathrm{~Hz}, 16 \mathrm{H}), 1.25-1.17(\mathrm{~m}, 16 \mathrm{H}), 1.14-1.08(\mathrm{~m}, 16 \mathrm{H}), 0.99-0.94(\mathrm{~m}$, broad, $16 \mathrm{H}), 0.81-0.76(\mathrm{~m}, 24 \mathrm{H})$, $0.70(\mathrm{t}, J=7.2 \mathrm{~Hz}, 24 \mathrm{H}), 0.66-0.55(\mathrm{~m}, 16 \mathrm{H}),-2.56(\mathrm{~s}, 2 \mathrm{H}) .{ }^{13} \mathrm{C} \mathrm{NMR}\left(125 \mathrm{MHz}, \mathrm{CDCl}_{3}, \mathrm{ppm}\right): \delta=$ 151.3, 150.0, 150.8, 149.6, 141.5, 141.4, 141.2, 140.5, 140.1, 133.8, 131.0, 130.6, 129.4, 127.5, 126.9, 126.1, 126.0, 122.9, 122.1, 121.5, 120.7, 120.1, 120.0, 119.7, 118.2, 90.9, 90.5, 55.4, 55.1, 40.3, 3.7, 26.4, 25.9, 23.1, 14.1, 14.0, 13.8. HRMS-ESI: $m / z$ calcd for $\mathrm{C}_{196} \mathrm{H}_{207} \mathrm{~N}_{4}: 2616.6237[\mathrm{M}+\mathrm{H}]^{+}$; found 2616.6227 and HRMS-MALDI: $m / z$ calcd for $\mathrm{C}_{196} \mathrm{H}_{206} \mathrm{~N}_{4}$ : 2615.6237 [M] $]^{+}$; found 2615.613. Anal. Calcd. (\%) for $\mathrm{C}_{196} \mathrm{H}_{206} \mathrm{~N}_{4}$ : C, 89.93; H, 7.93; N, 2.14. Found: C, 89.68; H, 7.90; N, 2.06.

Porphyrin Dendrimer TFP2. A mixture of dendron D2 (200 mg, $0.20 \mathrm{mmol}, 1 \mathrm{eq}$ ) and propionic acid $(3 \mathrm{~mL})$ was heated to $120{ }^{\circ} \mathrm{C}$ under stirring. A solution of pyrrole $(0.01 \mathrm{~mL}, 0.20 \mathrm{mmol}, 1 \mathrm{eq})$ in propionic acid $(0.3 \mathrm{~mL})$ was then added dropwise. The mixture was refluxed for $5.5 \mathrm{~h}$. After cooling to room temperature, $\mathrm{MeOH}$ was added, leading to a precipitate, which was filtered. Purification by chromatography eluting with petroleum ether $/ \mathrm{CH}_{2} \mathrm{Cl}_{2}$ mixtures $(5: 1)$, afforded a red powder, which was recrystallized from $\mathrm{CHCl}_{3}$ and $\mathrm{MeOH}$, leading to TFP2 as a purple powder (40 mg, $19 \%$ yield). ${ }^{1} \mathrm{H}$ NMR (400 MHz, $\left.\mathrm{CDCl}_{3}, \mathrm{ppm}\right): \delta=8.94$ (s, 8H), 8.27-8.23 (m, 8H), 8.11 (d, $\left.J=7.2 \mathrm{~Hz}, 4 \mathrm{H}\right), 7.97$ (d, $J$ 
$=7.6 \mathrm{~Hz}, 4 \mathrm{H}), 7.79-7.77(\mathrm{~m}, 12 \mathrm{H}), 7.72-7.68(\mathrm{~m}, 24 \mathrm{H}), 7.56-7.54(\mathrm{~m}, 16 \mathrm{H}), 7.36-7.32(\mathrm{~m}, 24 \mathrm{H}), 2.18$ (broad, 16H), $2.01(\mathrm{t}, J=8.0 \mathrm{~Hz}, 32 \mathrm{H}), 1.26-1.19(\mathrm{~m}, 16 \mathrm{H}), 1.16-1.06(\mathrm{~m}, 32 \mathrm{H}), 1.03-0.93$ (m, broad, $16 \mathrm{H}), 0.83-0.77(\mathrm{~m}, 24 \mathrm{H}), 0.70(\mathrm{t}, J=7.4 \mathrm{~Hz}, 48 \mathrm{H}), 0.65-0.54(\mathrm{~m}, 32 \mathrm{H}),-2.56(\mathrm{~s}, 2 \mathrm{H}) .{ }^{13} \mathrm{C} \mathrm{NMR}(125$ $\left.\mathrm{MHz}, \mathrm{CDCl}_{3}, \mathrm{ppm}\right): \delta=151.4,151.1,150.8,149.6,141.8,141.6,141.5,140.3,140.0,133.9,131.1$, $130.7,129.4,127.6,126.9,126.3,126.1,124.3,124.2,122.9,121.5,120.9,120.7,120.2,120.1,119.7$, 118.3, 91.7, 88.3, 88.0, 55.4, 55.1, 40.3, 40.2, 29.7, 26.4, 25.9, 23.1, 14.1, 14.0, 13.8. HRMS-ESI: $\mathrm{m} / \mathrm{z}$ calcd for $\mathrm{C}_{320} \mathrm{H}_{319} \mathrm{~N}_{4}: 4217.50793[\mathrm{M}+\mathrm{H}]^{+}$; found 4217.5171 and calcd for $\mathrm{C}_{320} \mathrm{H}_{319} \mathrm{~N}_{4}: 2108.75369$ $\left[\mathrm{M}_{2}+2 \mathrm{H}\right]^{++}$; found 2108.7442. Anal. Calcd. (\%) for $\mathrm{C}_{320} \mathrm{H}_{318} \mathrm{~N}_{4}: \mathrm{C}, 91.08 ; \mathrm{H}, 7.60 ; \mathrm{N}, 1.33$. Found: C, $90.88 ; \mathrm{H}, 7.53 ; \mathrm{N}, 1.20$.

Porphyrin Dendrimer TFP3. A mixture of dendron D3 (240 mg, $0.10 \mathrm{mmol}, 1 \mathrm{eq}$ ) and propionic acid $(4 \mathrm{~mL})$ was heated to $120{ }^{\circ} \mathrm{C}$ under stirring. A solution of pyrrole $(0.007 \mathrm{~mL}, 0.10 \mathrm{mmol}, 1 \mathrm{eq})$ in propionic acid $(0.5 \mathrm{~mL})$ was then added dropwise. The mixture was refluxed for $5.5 \mathrm{~h}$. Solvents were evaporated, and the residue was adsorbed on silica and further purified by chromatography eluting with petroleum ether / $\mathrm{CH}_{2} \mathrm{Cl}_{2}$ mixtures (5:1), affording $\mathbf{T F P 3}$ as a red powder (2 mg, $1 \%$ yield). ${ }^{1} \mathrm{H}$ NMR (400 MHz, $\left.\mathrm{CDCl}_{3}, \mathrm{ppm}\right): \delta=8.94(\mathrm{~s}, 8 \mathrm{H}), 8.29-8.23(\mathrm{~m}, 8 \mathrm{H}), 8.12(\mathrm{~d}, J=8.4 \mathrm{~Hz}, 4 \mathrm{H}), 7.98(\mathrm{~d}, J=7.6$ $\mathrm{Hz}, 4 \mathrm{H})$, 7.81-7.79 (m, 12H), 7.75-7.69 (m, 76H), 7.59-7.53 (m, 68H), 7.36-7.32 (m, 48H), 2.19 (broad, $16 \mathrm{H}), 2.09-1.98$ (m, 96H), 1.26-1.22 (m, 16H), 1.16-1.06 (m, 96H), 0.99-0.94 (broad, 16H), 0.85-0.80 (m, 24H), 0.75-0.67 (m, 144H), 0.65-0.55 (m, 96H), -2.55 (s, 2H). $\left.{ }^{13} \mathrm{C} \mathrm{NMR} \mathrm{(125} \mathrm{MHz,} \mathrm{CDCl}_{3}, \mathrm{ppm}\right): \delta$ $=151.2,151.0,150.8,148.8,143.2,141.8,141.0,140.9,140.3,140.0,133.9,133.8,131.1,130.9,130.7$, 127.6, 126.9, 126.1, 124.3, 124.1, 124.0, 122.9, 121.6, 120.9, 120.7, 120.1, 120.0, 119.7, 91.7, 91.6, 91.5, 88.4, 87.9, 55.4, 55.2, 55.0, 40.2, 29.7, 29.4, 26.3, 25.9, 23.0, 14.1, 14.0, 13.8. HRMS-MALDI: $m / z$ calcd for $\mathrm{C}_{752} \mathrm{H}_{734} \mathrm{~N}_{4}: 9828.9364[\mathrm{M}]^{+}$; found 9828.69.

Spectroscopic Measurements. All photophysical properties have been performed with freshly-prepared air-equilibrated solutions at room temperature (298 K). UV-Vis absorption spectra were recorded on a BIO-TEK instrument UVIKON XL spectrometer or on a Jasco V-570 spectrophotometer. Steady-state fluorescence measurements were performed on dilute solutions ( $c a$. $10^{-6} \mathrm{M}$, optical density $\left.<0.1\right)$ contained in standard $1 \mathrm{~cm}$ quartz cuvettes using an Edinburgh Instrument (FLS920) spectrometer in photon-counting mode. Fully corrected emission spectra were 
obtained, for each compound, after excitation at the wavelength of the absorption maximum, with $A_{\lambda \mathrm{ex}}$ $<0.1$ to minimize internal absorption.

Measurements of singlet oxygen quantum yield $\left(\Phi_{\Delta}\right)$. Measurements were performed on a Fluorolog-3 (Horiba Jobin Yvon), using a $450 \mathrm{~W}$ Xenon lamp. The emission at $1272 \mathrm{~nm}$ was detected using a liquid nitrogen-cooled Ge-detector model (EO-817L, North Coast Scientific Co). Singlet oxygen quantum yields $\Phi_{\Delta}$ were determined in dichloromethane solutions, using tetraphenylporphyrin (TPP) in dichloromethane as reference solution $\left(\Phi_{\Delta}[\mathrm{TPP}]=0.60\right)$ and were estimated from ${ }^{1} \mathrm{O}_{2}$ luminescence at $1272 \mathrm{~nm}$.

Two-Photon Absorption Experiments. To span the 790-920 nm range, a Nd:YLF-pumped Ti:sapphire oscillator (Chameleon Ultra, Coherent) was used generating $140 \mathrm{fs}$ pulses at a $80 \mathrm{MHz}$ rate. The excitation power is controlled using neutral density filters of varying optical density mounted in a computer-controlled filter wheel. After five-fold expansion through two achromatic doublets, the laser beam is focused by a microscope objective (10x, NA 0.25 , Olympus, Japan) into a standard $1 \mathrm{~cm}$ absorption cuvette containing the sample. The applied average laser power arriving at the sample is typically between 0.5 and $40 \mathrm{~mW}$, leading to a time-averaged light flux in the focal volume on the order of $0.1-10 \mathrm{~mW} / \mathrm{mm}^{2}$. The fluorescence from the sample is collected in epifluorescence mode, through the microscope objective, and reflected by a dichroic mirror (Chroma Technology Corporation, USA; "blue" filter set: $675 \mathrm{dcx} u$; "red" filter set: $780 \mathrm{dxcrr})$. This makes it possible to avoid the inner filter effects related to the high dye concentrations used $\left(10^{-4} \mathrm{M}\right)$ by focusing the laser near the cuvette window. Residual excitation light is removed using a barrier filter (Chroma Technology; "blue": e650 2p, "red": e750sp-2p). The fluorescence is coupled into a $600 \mu \mathrm{m}$ multimode fiber by an achromatic doublet. The fiber is connected to a compact CCD-based spectrometer (BTC112-E, B\&WTek, USA), which measures the two-photon excited emission spectrum. The emission spectra are corrected for the wavelength-dependence of the detection efficiency using correction factors established through the measurement of reference compounds having known fluorescence emission spectra. Briefly, the set-up allows for the recording of corrected fluorescence emission spectra under multiphoton excitation at variable excitation power and wavelength. TPA cross sections $\left(\sigma_{2}\right)$ were determined from the two-photon excited fluorescence (TPEF) cross sections $\left(\sigma_{2} . \Phi_{\mathrm{F}}\right)$ and the fluorescence emission quantum 
yield $\left(\Phi_{\mathrm{F}}\right)$. TPEF cross sections of $10^{-4} \mathrm{M}$ dichloromethane solutions were measured relative to fluorescein in $0.01 \mathrm{M}$ aqueous $\mathrm{NaOH}$ using the well-established method described by $\mathrm{Xu}$ and $\mathrm{Webb}^{[23]}$ and the appropriate solvent-related refractive index corrections. ${ }^{[28]}$ The quadratic dependence of the fluorescence intensity on the excitation power was checked for each sample and all wavelengths.

\section{- ASSOCIATED CONTENT}

Supporting Informations. ${ }^{1} \mathrm{H}$ NMR and ${ }^{13} \mathrm{C}$ NMR and mass spectra of all new compounds. This material is available free of charge via the Internet at http://pubs.acs.org.

\section{- AUTHOR INFORMATION}

\section{Corresponding Author}

*Email: christine.paul@univ-rennes1.fror christine.paul@insa-rennes.fr

\section{- ACKNOWLEDGEMENTS}

The authors acknowledge China Scholarship Council (CSC) for PhD funding (DY and XZ). We also thank Vincent Hugues and Guillaume Clermont (ISM) for their help in the two-photon and singlet oxygen measurements.

\section{REFERENCES AND NOTES}

(1) (a) Gao, Y.; Zhang, X.; Ma, C. ; Li, X. ; Jiang, J. J. Am. Chem. Soc., 2008, 130,17044-17052. (b) Drouet, S.; Ballut, S.; Rault-Berthelot, J.; Turban, P.; Paul-Roth, C. Thin Solid Films 2009, 517, 5474-5481. (c) Drouet, S.; Merhi, A.; Argouarch, G.; Paul, F.; Mongin, O.; Blanchard-Desce, M.; Paul-Roth, C. O. Tetrahedron 2012, 68, 98-105.

(2) (a) Schmittel, M.; Samanta, S. K. J. Org. Chem. 2010, 75, 5911-5919. (b) Tomizaki, K.-Y.; Yu, L.; Wei, L.; Bocian, D. F.; Lindsey, J. S. J. Org. Chem., 2003, 68, 8199-8207. (c) Richardson, C.; Reed, C. A. J. Org. Chem. 2007, 72, 4750-4755. (d) Nakano, A.; Yasuda, Y.; 
Yamazaki, T.; Akimoto, S.; Yamazaki, I.; Miyasaka, H.; Itaya, A.; Murakami, M.; Osuka, A. J. Phys. Chem. A 2001, 105, 4822-4833. (e) Kumaresan, D.; Agarwal, N.; Ravikanth, M. J. Chem. Soc., Perkin Trans. 1 2001, 1644-1648.

(3) (a) Lebedev, A. Y.; Cheprakov, A. V.; Sakadzic, S.; Boas, D. A.; Wilson, D. F.; Vinogradov, S. A. Applied Materials \& Interfaces 2009, 1, 1292-1304. (b) Severance, S.; Hamza, I. Chem. Rev. 2009, 109, 4596-4616.

(4) (a) Verma, S.; Ghosh, H. N. J. Phys. Chem. Lett. 2012, 3, 1877-1884. (b) Huang, C.; Wang, N.; Li, Y.; Li, C.; Li, J. Macromolecules 2006, 39, 5319-5325. (c) Nowakowska, M. ; Kataoka, F. ; Guillet, J. E. Macromolecules 1996, 29, 1600-1608. (d) Matos, M. S.; Hofkens, J.; Verheijen, W.; Schryver, F. C. D.; Hecht, S.; Pollak, K. W.; Frechet, J. M. J.; Forier, B.; Dehaen, W. Macromolecules 2000, 33, 2967-2973.

(5) (a) Juan, O.; Helqe, M.-B.; Martin, A. Chem. Commun. 2014, 50, 3488-3490. (b) Ema, T.; Miyazaki, Y.; Shimonishi, J.; Maeda, C.; Hasegawa, J.-Y. J. Am. Chem. Soc. 2014, 136, 15270-15279. (c) Jiang,Q.; Sheng, W.; Tian, M.; Tang, J.; Guo, C. Eur. J. Org. Chem. 2013, 1861-1866. (d) Paul-Roth, C.; Rault-Berthelot, J.; Simonneaux, G. Tetrahedron 2004, 60, 12169-12175. (e) Paul-Roth, C.; Rault-Berthelot, J.; Simonneaux, G.; Poriel, C.; Abdalilah, M.; Letessier, J. J. Electroanal. Chem. 2006, 597, 19-27.

(6) (a) Kozaki, M.; Uetomo, A.; Suzuki, S.; Okada, K. Org. Lett. 2008, 10, 4477-4480. (b) Nielsen, K. T.; Spanggaard, H.; Frebs, F. C. Macromolecules 2005, 38, 1180-1189. (c) Uetomo, A.; Kozaki, M.; Suzuki, S.; Yamanaka, K.-i.; Ito, O.; Okada, K. J. Am. Chem. Soc. 2011, 133, 13276-13279.

(7) (a) Frampton, M. J.; Beavington, R.; Lupton, J. M.; Samuel, I. D. W.; Burn, P. L. Synth. Met. 2001, 121, 1671-1672. (b) Pillow, J. N. G.; Halim, M.; Lupton, J. M.; Burn, P. L.; Samuel, I. D. W. Macromolecules 1999, 32, 5985-5993. (c) Kozaki, M.; Akita, K.; Suzuki, S.; Okada, K. Org. Lett., 2007, 9, 3315-3318. (d) O. Mongin, M. Sankar, M. Charlot, Y. Mir, M. Blanchard-Desce, Tetrahedron Lett. 2013, 54, 6474-6478.

(8) (a) Li, B.; Li, J.; Fu, Y.; Bo, Z. J. Am. Chem. Soc. 2004, 126, 3430-3431. (b) Li, B.; Xu, X.; Sun, M.; Fu, Y.; Yu, G.; Liu, Y.; Bo, Z. Macromolecules 2006, 39, 456-461.

(9) (a) Dichtel, W. R.; Serin, J. M.; Edder, C.; Fréchet, J. M. J.; Matuszewski, M.; Tan, L.-S.; Ohulchanskyy, T. Y.; Prasad, P. N. J. Am. Chem. Soc. 2004, 126, 5380-5381. (b) Oar, M. A.; 
Dichtel, W. R.; Serin, J. M.; Fréchet, J. M. J. Chem. Mater. 2006, 18, 3682-3692.

(10) Harth, E. M.; Hecht, S.; Helms, B.; Malmstrom, E. E.; Fréchet, J. M. J.; Hawker, C. J. J. Am. Chem. Soc. 2002, 124, 3926-3938.

(11) Wang, X.; Wang, H.; Yang, Y.; He, Y.; Zhang, L.; Li, Y.; Li, X. Macromolecules 2010, 43, 709-715.

(12) (a) Paul-Roth, C. O.; Simonneaux, G. Tetrahedron Lett. 2006, 47, 3275-3278. (b) Paul-Roth, C. O.; Simonneaux, G. C.R. Acad. Sci., Ser. IIb: Chim. 2006, 9, 1277-1286.

(13) (a) Paul-Roth, C. O.; Williams, J. A. G.; Letessier, J.; Simonneaux, G. Tetrahedron Lett. 2007, 48, 4317-4322. (b) Drouet, S.; Paul-Roth, C. O.; Fattori, V.; Cocchi, M.; Williams, J. A. G. New J. Chem. 2011, 35, 438-444. (c) Paul-Roth, C. O.; Drouet, S.; Merhi, A.; Williams, J. A. G.; Gildea, L. F.; Pearson, C.; Petty, M. C. Tetrahedron 2013, 69, 9625-9632.

(14) (a) Drouet, S.; Paul-Roth, C.; Simonneaux, G. Tetrahedron 2009, 65, 2975-2981. (b) Drouet, S.; Paul-Roth, C. O. Tetrahedron 2009, 65, 10693-10700. (c) Merhi, A.; Drouet, S.; Kerisit, N.; Paul-Roth, C. O. Tetrahedron 2012, 68, 7901-7910.

(15) (a) Devi, C. L.; Yesudas, K.; Makarov, N. S.; Rao, V. J.; Bhanuprakash, K.; Perry, J. W. J. Mater. Chem. C. 2015, 3, 3730-3744. (b) C. Rouxel, M. Charlot, O. Mongin, T. R. Krishna, A.-M. Caminade, J.-P. Majoral, M. Blanchard-Desce, Chem. Eur. J. 2012, 18, 16450-16462. (c) A. Triadon, F. Malvolti, F. Paul, M. Humphrey et al. work in progress. (d) Yao, D.; Hugues, V.; Blanchard-Desce, M.; Mongin, O.; Paul-Roth, C. O.; Paul, F. New J. Chem. 2015, 39, 7730-7733. (e) Yao, D.; Zhang, X.; Mongin, O.; Paul, F.; Paul-Roth, C. O. Chem. Eur. J. 2016, $22,5583-5597$.

(16) (a) F. Figueira, P. M. R. Pereira, S. Silva, J. A. S. Cavaleiro and J. P. C. Tomé, Current Org. Synth. 2014, 11, 110-126. (b) L. B. Josefsen and R.W. Boyle, Theranostics, 2012, 2, 916-966. (c) M. Khurana, H. A. Collins, A. Karotki, H. L. Anderson, D. T. Cramb, B. C. Wilson, Photochem. Photobiol., 2007, 83,1441; (d) J. R. Starkey, A. K. Rebane, M. A. Drobizhev, F. Meng, A. Gong, A. Elliott, K. McInnerney, C. W. Spangler, Clin. Cancer Res., 2008, 14, 6564-6573. (e) Collins, H. A.; Khurana, M.; Moriyama, E. H.; Mariampillai, A.; Dahlstedt, E.; Balaz, M.; Kuimova, M. K.; Drobizhev, M.; Yang, V. X. D.; Phillips, D.; Rebane, A.; Wilson, B. C.; Anderson, H. L. Nature Photonics 2008, 2, 420-424. (f) P. Prabhu, V. Patravale, J. Biomed. Nanotechnol. 2012, 8, 859-882. (g) J. Bhaumik, A. K. Mittal, A. Banerjee, Y. Chisti, U. C. 
Banerjee, Nano Res. 2015, 8, 1373-1394.

(17) G. Marzari, J. Durantini, D. Minudri, M. Gervaldo, L. Otero, F. Fungo, G. Pozzi, M. Cavazzini, S. Orlandi, S. Quici, J. Phys. Chem. C 2012, 116, 21190-21200.

(18) (a) Fang, Z.; Liu, B. Tetrahedron Lett. 2008, 49, 2311-2315. (a) Richardson, C.; Reed, C. A. J. Org. Chem. 2007, 72, 4750-4755.

(19) (a) Borst, M. L. G.; Bulo, R. E.; Gibney, D. J.; Alem, Y.; de Kanter, F. J. J.; Ehlers, A. W.; Schakel, M.; Lutz, M.; Spek, A. L.; Lammertsma, K. J. Am. Chem. Soc. 2005, 127, 16985-16999. (b) Sahu, B.; Muruganantham, R.; Namboothiri, I. N. N. Eur. J. Org. Chem. 2007, 2477-2489. (c) Polyansky, D. E.; Danilov, E. O.; Voskresensky, S. V.; Rodgers, M. A. J.; Neckers, D. C. J. Am. Chem. Soc. 2005, 127, 13452-13453.

(20) (a) Ranger, M.; Leclerc, M. Macromolecules 1999, 32, 3306-3313. (b) Fei, Z.; Li, B.; Bo, Z.; Lu, R. Org. Lett. 2004, 6, 4703-4706.

(21) (a) Adler, A. D.; Longo, F. R.; Finarelli, J. D.; Goldmacher, J.; Assour, J.; Korsakoff, L. J. Org. Chem. 1967, 32, 476-476. (b) Kim, J. B.; Adler, A. D.; Longo, F. R. In : The Porphyrins; Dolphin, D., Ed.; Academic Press: New-York 1978, Vol. 1, Part A, p 85.

(22) (a) O. Mongin, L. Porrès, M. Charlot, C. Katan, M. Blanchard-Desce, Chem. Eur. J. 2007, 13, 1481-1498. (b) N. I. Nijegorodov and W. S. Downey, J. Phys. Chem. 1994, 98, 5639-5643.

(c) Seybold, P. G.; Gouterman, M. J. Mol. Spectroscopy 1969, 31, 1-13.

(23) Xu, C.; Webb, W. W. J. Opt. Soc. Am. B 1996, 13, 481-491.

(24) Makarov, N. S.; Drobizhev, M.; Rebane, A. Opt. Express 2008, 16, 4029-4047.

(25) (a) Drobizhev, M.; Stepanenko, Y.; Dzenis, Y.; Karotki, A.; Rebane, A.; Taylor, P. N.; Anderson, H. L. J. Am. Chem. Soc. 2004, 126, 15352-15353; (b) Kim, D. Y.; Ahn, T. K.; Kwon, J. H.; Kim, D.; Ikeue, T.; Aratani, N.; Osuka, A.; Shigeiwa, M.; Maeda, S. J. Phys. Chem. A 2005, 109, 2996-2999; (c) Drobizhev, M.; Stepanenko, Y.; Dzenis, Y.; Karotki, A.; Rebane, A.; Taylor, P. N.; Anderson, H. L. J. Phys. Chem. B 2005, 109, 7223-7236; (d) Ahn, T. K.; Kim, K. S.; Kim, D. Y.; Noh, S. B.; Aratani, N.; Ikeda, C.; Osuka, A.; Kim, D. J. Am. Chem. Soc. 2006, 128, 1700-1704; (e) Ogawa, K.; Hasegawa, H.; Inaba, Y.; Kobuke, Y.; Inouye, H.; Kanemitsu, Y.; Kohno, E.; Hirano, T.; Ogura, S.-i.; Okura, I. J. Med. Chem. 2006, 49, 2276-2283; (f) Achelle, S.; Couleaud, P.; Baldeck, P.; Teulade-Fichou, M.-P.; Maillard, P. Eur. J. Org. Chem. 2011, 2011, 1271-1279; (g) Hammerer, F.; Achelle, S.; Baldeck, P.; 
Maillard, P.; Teulade-Fichou, M.-P. J. Phys. Chem. A 2011, 115, 6503-6508; (h) Pawlicki, M.;

Morisue, M.; Davis, N. K. S.; McLean, D. G.; Haley, J. E.; Beuerman, E.; Drobizhev, M.;

Rebane, A.; Thompson, A. L.; Pascu, S. I.; Accorsi, G.; Armaroli, N.; Anderson, H. L. Chem. Sci. 2012, 3, 1541-1547.

(26) (a) There is a large dihedral angle between the meso-aryl substituent and the macrocycle, which is more than $60^{\circ}$ in the case of TPP, see: Silvers, S. J.; Tulinsky, A. J. Am. Chem. Soc. 1967, 89, 3331-3337. (b) Mongin, O.; Hugues, V.; Blanchard-Desce, M.; Merhi, A.; Drouet, S.; Yao, D.; Paul-Roth, C. Chem. Phys. Lett. 2015, 625, 151-156.

(27) Perrin, D. D.; Armarego, W. L. F. Purification of Laboratory Chemicals, 3rd edn., Pergamon Press, Oxford, 1988.

(28) Werts, M. H. V.; Nerambourg, N.; Pélégry, D.; Le Grand, Y.; Blanchard-Desce, M. Photochem. Photobiol. Sci. 2005, 4, 531-538. 